Portland State University

PDXScholar

1996

\title{
Government Policy and Private Organizational \\ Forms: Analysis of Refuse Collection and Disposal in Three Metropolitan Cities
}

Thomas Wright

Portland State University

Follow this and additional works at: https://pdxscholar.library.pdx.edu/open_access_etds

Part of the Urban Studies and Planning Commons

Let us know how access to this document benefits you.

Recommended Citation

Wright, Thomas, "Government Policy and Private Organizational Forms: Analysis of Refuse Collection and Disposal in Three Metropolitan Cities" (1996). Dissertations and Theses. Paper 1175.

https://doi.org/10.15760/etd.1174

This Dissertation is brought to you for free and open access. It has been accepted for inclusion in Dissertations and Theses by an authorized administrator of PDXScholar. Please contact us if we can make this document more accessible: pdxscholar@pdx.edu. 


\section{INFORMATION TO USERS}

This manuscript has been reproduced from the microfilm master. UMI films the text directly from the original or copy submitted. Thus, some thesis and dissertation copies are in typewriter face, while others may be from any type of computer printer.

The quality of this reproduction is dependent upon the quality of the copy submitted. Broken or indistinct print, colored or poor quality illustrations and photographs, print bleedthrough, substandard margins, and improper alignment can adversely affect reproduction.

In the unlikely event that the author did not send UMI a complete manuscript and there are missing pages, these will be noted. Also, if unauthorized copyright material had to be removed, a note will indicate the deletion.

Oversize materials (e.g., maps, drawings, charts) are reproduced by sectioning the original, beginning at the upper left-hand corner and continuing from left to right in equal sections with small overlaps. Each original is also photographed in one exposure and is included in reduced form at the back of the book.

Photographs included in the original manuscript have been reproduced xerographically in this copy. Higher quality 6" x 9" black and white photographic prints are available for any photographs or illustrations appearing in this copy for an additional charge. Contact UMI directly to order.

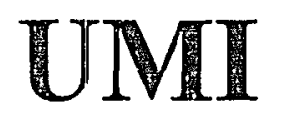

A Bell \& Howell Information Company 300 North Zeeb Road, Ann Arbor MI 48106-1346 USA $313 / 161-4700 \quad 800 / 521-0600$ 
GOVERNMENT POLICY AND PRIVATE ORGANIZATIONAL FORMS:

ANALYSIS OF REFUSE COLLECTION AND DISPOSAL

IN THREE METROPOLITAN CITIES

\author{
by
}

\title{
THOMAS WRIGHT
}

A dissertation submitted in partial fulfillment of the requirements for the degree of

\author{
DOCTOR OF PHILOSOPHY \\ in \\ URBAN STUDIES
}

Portland State University

(C) 1996 
UMI Number: 9627255

Copyright 1996 by

Wright, Thomas Junior

All rights reserved.

UMI Microform 9627255

Copyright 1996, by UMI Company. All rights reserved.

This microform edition is protected against unauthorized copying under Title 17, United States Code.

\section{UMI \\ 300 North Zeeb Road \\ Ann Arbor, MI 48103}




\section{DISSERTATION APPROVAL}

The abstract and dissertation of Thomas Wright for the Doctor of Philosophy in Urban Studies was presented January 30, 1996, and accepted by the dissertation committee and the doctoral program. COMMITTEE APPROVALS:

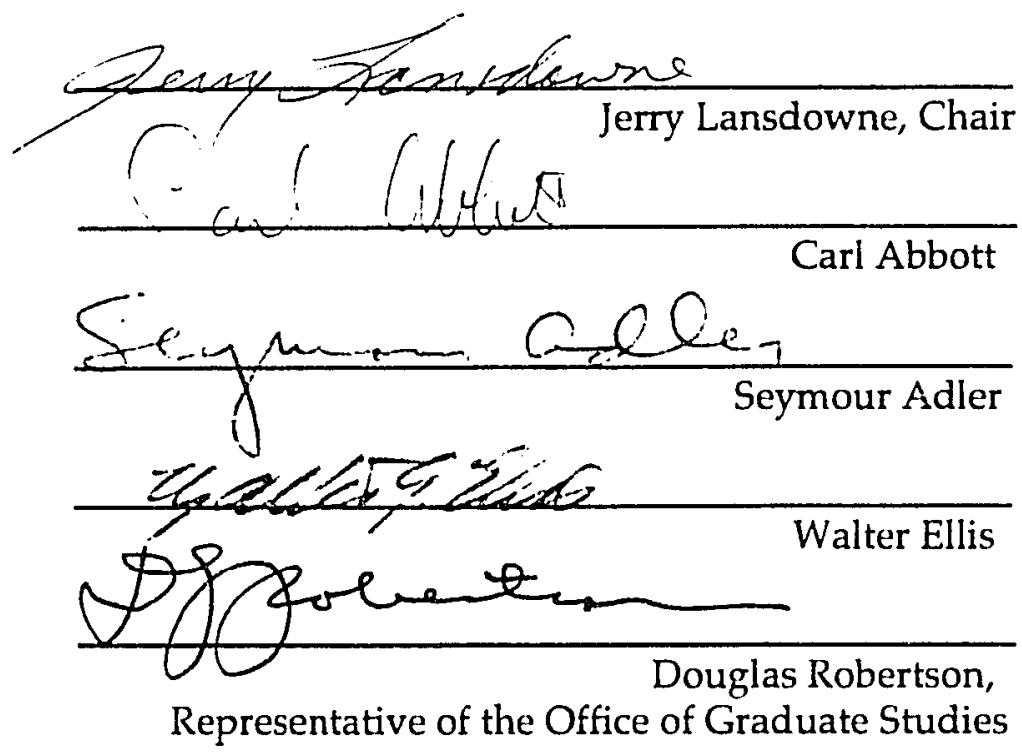

DOCTORAL PROGRAM APPROVAL:

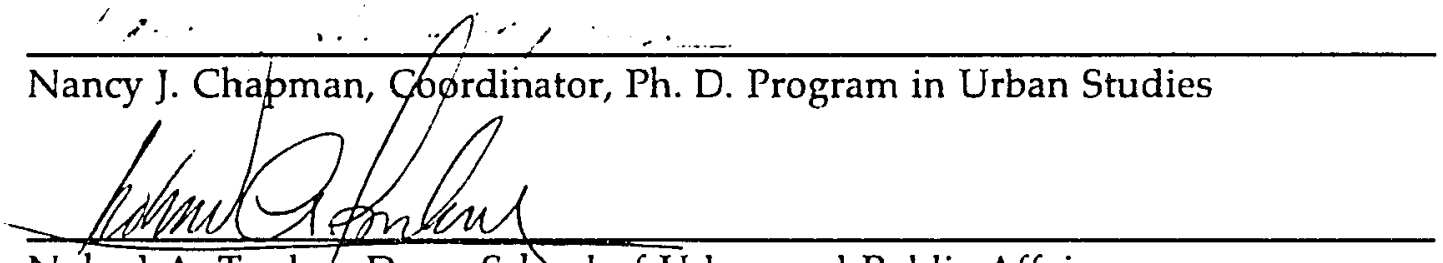

Nohad A. Toulan, Dean, School of Urban and Public Affairs

ACCEPTED FOR PORTLAND STATE UNIVERSITY LIBRARY

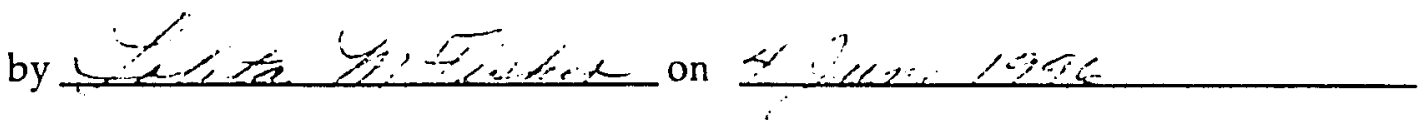




\begin{abstract}
An abstract of the dissertation of Thomas Wright for the Doctor of Philosophy in Urban Studies presented January 30, 1996.

Title: Government Policy and Private Organizational Forms: Analysis of Refuse Collection and Disposal in Three Metropolitan Cities.

This study explores refuse collection as a municipal service using qualitative methods to examine how government makes decisisons about residential refuse collection services in Portland, Gresham, and Beaverton, Oregon. The study explores the history of refuse collection in these three cities to identify factors that influence bureaucratic behavior and decision making when selecting a municipal service delivery option for refuse collection.
\end{abstract}

Public choice and public policy analysis theory are used to discuss those non-monetary considerations present when government makes decisions about service arrangements.

Qualitative data was collected from public officials and private haulers involved in refuse collection in the three cities. This qualitative process was to capture, in context, the development of the industry.

The use of a single criterion in determining choice of private organizational forms may not create the results desired by municipal governments. Choice in the selection of a service arrangement has two 
important aspects: 1 . the array of service arrangement options that can be developed and 2. the contextual environment within which bureaucrats operate and which influences the decision making process.

It was found that decisions about which type of service arrangement to use for refuse collection did not always stem from monetary factors such as cost. Non-monetary factors such as tradition, legal considerations, and lobbying can influence decisions about which type of service arrangement to use. 


\section{ACKNOWLEDGEMENTS}

I want to acknowledge my family and friends who supported me during this dissertation process. I also want to thank my committee members. 
TABLE OF CONTENTS

PAGE

ACKNOWLEDGEMENTS $\ldots \ldots \ldots \ldots \ldots \ldots \ldots \ldots \ldots \ldots \ldots \ldots \ldots \ldots$ ii

LIST OF TABLES $\ldots \ldots \ldots \ldots \ldots \ldots \ldots \ldots \ldots \ldots \ldots \ldots \ldots \ldots \ldots \ldots \ldots$

CHAPTER

I INTRODUCTION $\ldots \ldots \ldots \ldots \ldots \ldots \ldots \ldots \ldots \ldots \ldots \ldots \ldots$

REFUSE COLLECTION: History, Changes, and Choices ....... 2

The History of Garbage $\ldots \ldots \ldots \ldots \ldots \ldots \ldots 2$

The Garbage Crisis $\ldots \ldots \ldots \ldots \ldots \ldots \ldots \ldots \ldots$. 5

Change in Oregon and the Three Cities ......... 10

The City of Portland

The City of Gresham

The City of Beaverton

Conceptual Framework $\ldots \ldots \ldots \ldots \ldots \ldots \ldots \ldots 22$

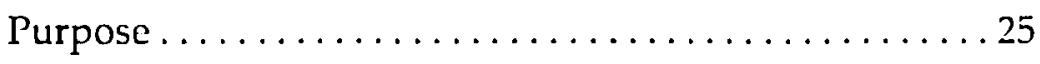

Summary $\ldots \ldots \ldots \ldots \ldots \ldots \ldots \ldots \ldots \ldots \ldots$

I $\quad$ SERVICE ARRANGEMENTS IN U.S. CITIES . . . . . . . 30

Introduction $\ldots \ldots \ldots \ldots \ldots \ldots \ldots \ldots \ldots \ldots \ldots \ldots \ldots \ldots \ldots \ldots$

Service Arrangements:

Municipal Collection .................... 34

Service Arrangements:

Portland, Gresham, Beaverton . . . . . . . . . . . 37

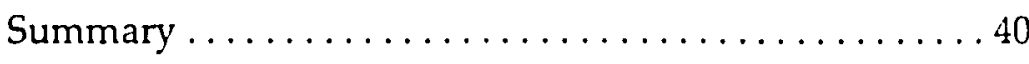


Overview $\ldots \ldots \ldots \ldots \ldots \ldots \ldots \ldots \ldots \ldots \ldots \ldots \ldots \ldots \ldots$

Municipal Services and Private Arrangements . . . . . 46

Bureaucratic Behavior ..................... 56

Decision-making $\ldots \ldots \ldots \ldots \ldots \ldots \ldots \ldots \ldots$

Summary $\ldots \ldots \ldots \ldots \ldots \ldots \ldots \ldots \ldots \ldots \ldots \ldots$

IV RESEARCHMETHODOLOGY $\ldots \ldots \ldots \ldots \ldots \ldots$

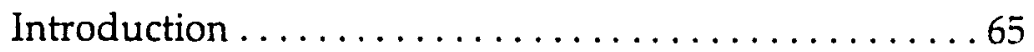

Research Design ..................66

Data Collection .....................68

Coding and Analysis $\ldots \ldots \ldots \ldots \ldots \ldots \ldots \ldots \ldots$

Limitations $\ldots \ldots \ldots \ldots \ldots \ldots \ldots \ldots \ldots \ldots \ldots \ldots \ldots$

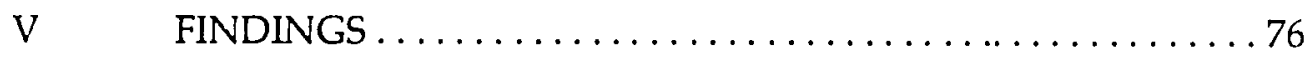

Introduction $\ldots \ldots \ldots \ldots \ldots \ldots \ldots \ldots \ldots \ldots \ldots$

Background $\ldots \ldots \ldots \ldots \ldots \ldots \ldots \ldots \ldots \ldots \ldots$

Tradition $\ldots \ldots \ldots \ldots \ldots \ldots \ldots \ldots \ldots \ldots \ldots$

Service Arrangements $\ldots \ldots \ldots \ldots \ldots \ldots \ldots \ldots$. 89

Bureaucracy ........................ 94

Change in the System ................ 102

Political Dynamics $\ldots \ldots \ldots \ldots \ldots \ldots \ldots \ldots \ldots \ldots$

Uniform Implementation $\ldots \ldots \ldots \ldots \ldots \ldots \ldots \ldots$

Recycling ........................ 127

Management Technologies ............... 130 
Summary $\ldots \ldots \ldots \ldots \ldots \ldots \ldots \ldots \ldots \ldots \ldots \ldots \ldots$

Overview $\ldots \ldots \ldots \ldots \ldots \ldots \ldots \ldots \ldots \ldots \ldots, 138$

Relevance of Literature ...................... 139

Evaluation of Themes ..................... 142

History

Tradition

Service Arrangements

Bureaucracy

Political Dynamics

Recycling

Management Technologies

Conclusion ............................ 156

Policy Implications $\ldots \ldots \ldots \ldots \ldots \ldots \ldots \ldots \ldots$

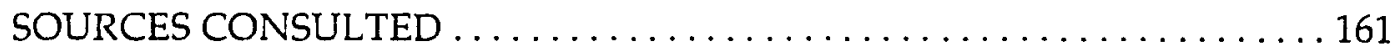

APPENDICES

A INFORMED CONSENT $\ldots \ldots \ldots \ldots \ldots \ldots \ldots \ldots \ldots \ldots \ldots \ldots \ldots$

B DEFINITIONS ............................. 174

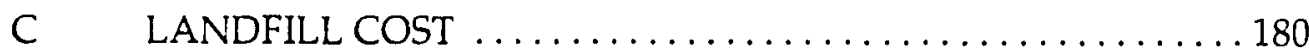




\section{LIST OF TABLES}

TABLE

PAGE

I

SERVICE ARRANGEMENT $\ldots \ldots \ldots \ldots \ldots \ldots, 38$

II

PARTICIPANTS ..................... 70

III MANAGEMENT TECHNOLOGIES ........... 132

IV MANAGEMENT TECHNOLOGIES ........... 133 


\section{Chapter 1}

\section{INTRODUCTION}

This dissertation explores refuse collection as a service arrangement for three cities in Oregon.

Chapter 1 discusses the waste disposal crisis and how Oregon has responded to that crisis. This chapter also explores changes in the refuse collection industry in Oregon: how decisions were made which stimulated proposals for change and translated into policies for garbage haulers. Changes began at the federal level and resulted in changes in State laws, which in turn created mandated changes at the local level. Decisions made in response to change effected both garbage haulers delivering the service and residents of the three cities. The three cities studied did not develop municipal collection as a service option.

Chapter 2 is a review of municipal refuse collections as a service arrangement, as well as a partial review of other alternative service arrangements used for the delivery of refuse collection services.

Chapter 3 is a review of literature relevant to alternative municipal service arrangements. The literature is also presented from the fields of Public Choice and Urban Policy Analysis. This chapter explores those nonmonetary considerations present when government makes decisions about service arrangements.

Chapter 4 lays out the methodology which guided the tasks of this 
study. Information was obtained through face to face interviews, public and private records, and the literature. This chapter delineates the data collection process and analysis of information on the development of refuse collection as a municipal service in the three cities.

Chapter 5 presents the findings on the development of refuse collection as a service in the three cities from the early 1900 s to present day service arrangements. This chapter is primarily a synthesis of the interview responses. Informants were asked questions that related to the history, traditions, service arrangements and programs, and political aspects of residential refuse collection in the three cities. Themes that developed during analysis are organized into the categories of Background, Tradition, Service Delivery Arrangements, Change in the System, Bureaucracy, Political Dynamics, Uniform Implementation, Recycling, and Management Technologies.

Chapter 6 summarizes and analyzes the findings from Chapter 5 and presents a discussion on implications for policy planners.

REFUSE COLLECTION: HISTORY, CHANGES, AND CHOICES

\section{The History of Garbage}

From the earliest periods of civilization, the process for the disposal of unwanted solid waste was simply to dump it into vacant land nearby (Wilson 1977). Until modern civilization, garbage was generally thrown onto an unpaved street or walkway where it was either reused by someone else or 
decomposed over time. Wilson (1977) has suggested that plagues and epidemics on entire continents were a result of inadequate or unsafe splid waste disposal methods. With the advent of urban living, new methods for the disposal of solid waste became a matter of health and safety for local citizens.

William $L_{n}$ Rathje (1990), citing the behaviors of the aborigines of the Australian outback, where they left debris in all the rooms and threw garbage out the windowsl and doors, has stated that, "As such behavior suggests, man faced his first garbage crisis when he became a sedentary animal" (p.33),

The problem of waste accumulation increased with the increase in population density. For urban areas without an organized disposal system, waste accumulated in the streets and other areas as people discarded unwanted items at will. This attitude could well account for the manner in which garbage was handled by individuals until laws forced changes in disposal methods.

Urban areas began to develop ordinances for refuse collection and disposal. David G. Wilson (1977) has reported that "an ordinance was directed in 1383 against those persons who had houses on the Walbrook and who, by throwing their refuse into the watercourse, had caused it to be stopped up to the great nuisance and damage of the city" (pp. 2-3). As populations become more concentrated and urban, better refuse collection and disposal practices were developed. Landfills were developed as a way to 
address concerns over the health hazards caused by indiscriminate dumping. In response to the need to pick up and dispose of solid waste from residential homes, a more formal process of collection and disposal of solid waste material was created as local jurisdictions developed public collection systems.

The refuse collection industry has also evolved because of scientific discoveries. For example, as new information becomes available about the potential health hazard some chemicals pose, changes must be made in the manner in which those chemicals are picked up from residential homes and then disposed of by the refuse hauler. Bellafante (1990), writing about toxic trash, has stated:

On route to the landfill, hazardous household waste can cause injuries to sanitation workers and damage to equipment. According to a 1982 California study, three percent of the garbage collectors in that State were hurt as a result of coming into contact with hazardous waste that had been tossed in residential trash cans. Chemicals can react with other substances in household trash, causing fire and explosion in trucks or waste-handling facilities. Once at the landfill, the toxins in hazardous household products can combine with rainwater and other liquids to form a particularly poisonous leachate, which may seep through the soil and contaminate groundwater. (p.45) After years of dumping trash in local dump sites, government officials have 
realized that this method for the disposal of unwanted items has created negative consequences for society and that different options are needed. The Garbage Crisis

The dimensions of the garbage crisis are complex and composed of competing dynamics that create contradictory demands. For example, the production of materials (i.e., plastics and styrofoam) has increased the standard of living for citizens and at the same time created the expectation that items wrapped in plastics are more sanitary, being untouched by human hands. But the packaging then must be disposed of. Consumer attitude (recycling-reuse) in the past has been one of a "throw away" mentality. It is estimated that each person produces as much as five to eight pounds of garbage each day (Rathje, 1990). There is more and more concern about toxic waste by-products (e.g., oil paint, cleaners, and pesticides) and their long lasting effects on natural resources such as the water supply and food chain. According to Ginia Bellafante (1990),

The average American household generates 15 pounds of hazardous waste per year. Most of it goes into local landfills, sewage-treatment plants, and septic tanks--all ill-equipped to handle toxins safely. An estimated 1.6 million tons of household hazardous waste exist in the municipal waste stream right now. (p. 44)

Waste produced by ordinary citizens continues to strain an already limited supply of landfill space. Beginning with refuse collection, disposal 
has complex issues and no easy answers. The impact of the continual build up of garbage combined with more rigid air, water, and land pollution controls helped the disposal problem reach serious proportions. Each day tons of new products are being produced in manufacturing plants for consumption by a public conditioned to expect clean and sanitary items when making a purchase. For example, a consumer expects a hamburger to be served in a clean and sanitary styrofoam container. That container after its use will be thrown away to become a part of the tons of garbage.

Each year landfills receive over 100 million tons of trash from residential households and businesses (Donahue, 1989). The World Wildlife Fund (1991) has reported that there were approximately 14,000 landfills operating in the United States in 1978 and that 45 percent of those landfills $(6,000)$ were expected to have reached authorized capacity by 1991 . Since landfills continue to be a primary method of disposing of unwanted materials, the question of what to do with all the garbage and how to manage its disposal becomes extremely important to public agencies as longstanding landfills close faster than new ones can be sited and developed. For example, in 1977 the Mobro 4000 barge searched for two months for a place to dump its load of garbage. Cities such as New York (Fresh Kills Landfill) and New Jersey (Cape May Landitil) have landfills that are filling up and using valuable land that is more suitable for other purposes (Breen, 1990). Environmental concerns about the types of materials being put in landfills and the seepage of 
toxic substances into the underground watershed has kept public attention both on the types of materials being put into landfills and on where landfills were being sited. The concern that there could be seepage of toxic substances into the landfill kept pressure on government to keep the toxic substances out of landfills. At the same time there has been the rapid depletion of currently operating landfills. The continued filling up of the landfills has forced the issue of new siting for disposal of garbage.

Bill Breen (1990) has indicated that 80 percent of the landfills in the United States are scheduled to close in the next 20 years and that, as costs rise for siting new landfills and meeting new environmental standards, replacing these landfills will become a very difficult process. Even where land space is available, the possibility of a new landfill being developed in a neighborhood triggers debate from citizens who do not want the landfill located in their neighborhood. The politics of "not in my back yard" makes the siting of a landfill even more difficult. It is no wonder that a movement has occurred in the U.S. to develop plans for dealing with the garbage crisis, Hlanna Holmes (1990) has indicated that land space is a premium commodity. Regarding public resistance to the siting of new landfills, Holmes makes this point:

It was a lack of landfill space and foresight which got many communities into the jams they're in now. As their leaky landfills reached capacity in the 1980 s, many municipalities belatedly looked for 
disposal options. What they found was enormous public resistance to new landfills and skyrocketing tipping fees. (p. 2-3)

This crisis is sustained by the behavior of people who continue to consume throwaway materials. For example, many bathroom products are produced using plastics instead of breakable glass materials. Safety may be the primary reason for the choice of plastics for products designed for bathroom consumption, but most glass products are recyclable, whereas there are limitations for recycling plastic products. In regard to competing social processes, Holmes (1990) has suggested that

The garbage mountains point up another important truth about garbage: Efficient disposal is not always completely compatible with other desirable social ends--due process, human dignity, economic modernization. In a liberal democracy, these other ends compete for priority. In the United States, a garbage problem is, in some respects, just the modest price we pay for having done many things right. (p.33) Since consumption behaviors / will not likely change enough to reduce the amount of garbage going to the landfill, the need for landfill space will probably continue. As Rathje (1990) has pointed out:

There are no ways of dealing with [garbage] which haven't been known for many thousands of years. As the species has advanced, people have introduced refinements, but the old ways are fundamentally still the only ways, and they are four: dumping garbage, burning garbage, 
turning garbage into something that can be used again, and minimizing the volume of material goods (future garbage) produced in the first place ('source reduction,' it's called). (p.33)

Rathje (1990) also suggests that a garbage crisis does in fact exist and has been with civilized humans for thousands of years. The problem has been identified and solutions of some sort have been applied to the problem of the build up of human waste.

Many solutions have been used to deal with garbage in the past, but as Rathje (1990) has pointed out, the options fall within a narrow range of alternatives. While any or and all of these options may be used, the landfill is still the primary method for disposal of garbage. The problem of managing the solid waste stream has prompted the introduction of new state laws regulating the disposal of unwanted materials. In search of solutions and in response to new laws, local governments have approached the problem from various points in the solid waste stream. In recognition of the problem, Congress passed the Solid Waste Disposal Act in 1965. The purpose of the act was to initiate research and development programs for solid waste disposal and to help State and local governments with technical and financial assistance in solid waste disposal programs. Federal legislation, such as the Solid Waste Disposal Act, the Municipal Solid Waste Source Reduction and Recycling Act, and the Waste Minimization and Control Act of 1989, was 
enacted to address environmental issues and to provide national direction for state and local governments.

Nationwide, it is city personnel who have been left with the decisions aboult what to do with the solid waste that continues to be generated. Many people in the industry saw time running out if no new sites were developed, and so they began developing alternative solutions to address the problem. One solution put forth was better regulation of solid waste to reduce the solid waste stream. This solution would consist of regulating the haulers to control waste at the entry point. Another solution could involve education. Education would stimulate interest in making better choices about the types of material they purchase as consumers. And another solution could be reuse and source reduction, along with recycling.

\section{Change in Oregon and the Three Cities}

In response to federal legislation, in 1991 the State of Oregon passed Senate Bill 66, which required cities and counties to reduce the amount of materials entering the solid waste stream. State policy created pressure for cities to reduce the amount of waste entering the landfills. Senate Bill 66 required jurisdictions with populations over 4000 to offer weekly curbside recycling as part of the waste reduction program. This included the collection of newspapers, glass bottles, tin cans, corrugated cardboard, aluminum, ferrous metals, non-ferrous metals, and motor oil and resulted in change at the local level. 
While State mandates were the impetus for local jurisdictions to adopt ordinances with the express goal of reducing the solid waste stream, it is worth noting that, before the garbage crisis was seen as being a crisis, the State of Oregon took action to reduce the amount of solid waste entering the solid waste stream. For example, Oregon became the first State in the nation to adopt a bottle bill which requires a deposit for most carbonated beverage containers. The bottle bill has been followed by additional legislation designed to reduce materials entering the solid waste stream. These legal mandates effected both the residents as consumers and the refuse collection haulers.

Change in the Oregon State Statutes forced local municipalities to change municipal policy regarding the collection and disposal of garbage, particularly regarding the type of garbage which would be sent to the landfills. The change in municipal policy, for how garbage would be regulated, created a change in organizational arrangements municipal governments had with the garbage haulers. Policies that changed included service arrangement agreements between the garbage haulers and the city governments.

While many changes were being implemented in refuse collection, the three cities left some areas untouched. For example, there is no mandated requirement that citizens use private haulers for refuse collection, and businesses are not affected by the new regulations for refuse collection for residential customers. While no citizen or corporation is allowed to violate 
health and safety laws, municipal policy in all three cities allows residents to choose how they want to dispose of their garbage. Historically, residents have been allowed to dispose of almost all residential garbage without hiring someone to do this for them. In effect, neither Portland, Gresham, nor Beaverton requires mandated garbage collection for residential refuse.

As noted earlier, Portland, Gresham, and Beaverton had not developed municipal refuse collection systems. Because there was no municipal collection system, the cities had no direct control over refuse collection either through policy or direct management; thus the cities lacked the legal mechanism to implement mandated requirements. The cities had to design a method to get private haulers to carry out the new State mandates that were being required of cities. The cities achieved this by changing the legal relationship between the cities and private haulers. Portland, Gresham, and Beaverton implemented new regulations for the pickup of residential refuse in order to give the cities more control so they could require such services as recycling. For example, the City of Portland which had been an open private competitive system, changed to a franchise system in 1992 in order to achieve its goal of reducing the solid waste stream. This is one of the ways in which the City of Portland has responded to the problem of closing landfills and new environmental laws. While municipal policy for refuse collection for Beaverton and Gresham had changed from an open system to a regulated system in the early 1970s, these cities made additional changes to previously 
adopted regulated refuse collection services in order to meet new programmatic changes such as yard debris collection. As recent as 1991, Portland had hundreds of garbage haulers picking up residential garbage. These haulers were crossing each other on the street in a most inefficient garbage hauling system. The need for change was clear: Refuse collection needed to change from simply picking up garbage and dumping it at a landfill to a process that included reducing the amount of solid waste entering the solid waste stream. State mandate to reduce solid waste from the waste stream was a key element that created the impetus in forcing refuse collection systems in the three cities to make changes. All three cities had to get more control of residentia! refuse collection services to meet State mandated goals. One of the first steps that the City of Portland had to take to get more control of residential refuse collection was to reduce the huge amount of overlap that existed in the service delivery system. Routes were combined to achieve efficiency, and minimum service level standards were established and implemented citywide. In Portland, many of the haulers were in favor of the new ordinance that provided for regulation because this protected their business interests by establishing franchising. Residential refuse haulers however, in most cases wanted to provide a service with the same quality as they had throughout the years.

The cities of Portland, Gresham, and Beaverton experienced a double crunch: Even as they were receiving new mandates to reduce the amount of 
refuse entering the waste stream, projected target closing dates for landfills were drawing near, and no new siting of land available for landfill development had been made. To achieve State mandated goals, new policies were implemented at the local level to reduce the amount of solid waste entering the solid waste stream. This was done by promoting environmentally sound practices with regard to residential refuse collection and the removal of materials from the solid waste stream either through recycling, reuse, or composting.

Once franchising was established in Portland changes were required from the residential customers as well as the garbage haulers. Coproduction was established as part of the overall programmatic (e.g., recycling) effort. Coproduction, essentially, requires the resident to activitely participate in the garbage collection and disposal process. Recycling brought with it the necessity for residents to activitely remove recyclables and reusable items from the solid waste stream. Prior to this emphasis on recycling, coproduction was not an essential part of the residential refuse collection process. Also a part of coproduction was the pricing structure, which encouraged the customer to reduce the size of the garbage can. The pricing structure in effect encouraged recycling and other activities which would reduce the size (and therefore cost) of the can needed for garbage.

Although the regulated system in Portland was implemented recently, and the cities of Beaverton and Gresham have had regulated systems for over 
20 years, the actual process for the pickup and disposal of garbage has remained unchanged for all three cities. In many cases, garbage companies in these three cities use the same landfill and transfer stations for the disposal of residential refuse. In recent years, the levels and types of service offered to residential customers have been adjusted to meet requirements set by Senate Bill 66. So, in many instances, all three cities with regulated service options function in the same manner.

In some cases, local bureaucrats and citizens were not that concerned about garbage collection. Garbage was simply garbage, and both City bureaucrats and the local citizens wanted only to get rid of it. Once the landfills began to reach maximum capacity, however, the bureaucrats who were responsible for solid waste management began to show concern for where solid waste would be put. In January 1990, Metro, the regional government in the Portland metropolitan area, started to require that garbage be sent to the Columbia Ridge Landfill in Arlington, about 140 miles east of Portland. This requirement began prior to the closing of the St. Johns Landfill. Since the St. Johns Landfill closure, almost all (around 90 percent of the non-recycled) garbage is sent to Arlington. Once the concept of limited space and a seemingly unlimited end to the generation of solid waste finally became a reality, government and concerned citizens became aware that a decision had to be made about the amount of garbage being generated and what sorts of garbage would be taken to the landfill. 
The City of Portland. The City of Portland, population 437,319 as of 1992, initiated a regulated franchised refuse collection and disposal system in February 1992. The refuse collection functions are located within the Bureau of Environmental Services. Portland's residential refuse collection system, as a service arrangement, changed from a private open competitive system to a regulated franchised system. Prior to regulation, the City had over 200 haulers picking up residential refuse. There were always private sector people willing to pick up garbage. In this private, open, competitive and unregulated system, haulers had minimum reporting requirements and needed only to have a City license and to provide a customer list to be in business in the City. The garbage haulers made corporate decisions about the type of trucks they would operate and picked up garbage in a manner that best served their customers and their company. In the past, garbage haulers had wanted regulation from the City but did not want the City to adopt a municipal residential collection service. In general, there was a belief that there would be public opposition to government adopting a municipal collection system and putting private haulers out of business. Private haulers wanted regulation because the industry was becoming more competitive, more complicated, and more costly to operate in order to meet new requirements. One of those new requirements was recycling. Recycling became one of the central issues for the Portland refuse collection industry.

To achieve the State mandated goals in the recovery of materials, to 
promote recycling participation, and to promote the efficient operation of the solid waste collection system in Portland, the Bureau of Environmental Services recommended that a franchise system be established wherein every licensed refuse collector in Portland was offered either a new license for the collection of residential garbage in a set territory or an assigned route. The routes were organized into six districts, and a franchise fee was assessed based on the collector's gross annual revenues, not to exceed five percent of the collector's gross annual fees. The City of Portland set rates so that the haulers could recover costs to deliver services and make a fair profit. Under the residential solid waste franchise system, garbage haulers are also required to provide recycling services and yard debris disposal services to residential customers. Under the regulated system, the requirements have become structured to include rate settings, route assignments, levels of service delivery by the haulers, standardized reporting, and customer relations. The City of Portland, in an effort to achieve environmental goals, adopted policy with these provisions:

- Reduce the generation of solid waste by 10 percent by 1997.

- Ensure the safe collection and hauling of solid waste.

-Provide recycling opportunities. 
- Establish standards for and educate the public about recycling and environmental awareness.

The administrative rules for solid waste and recycling collection are extensive. Definitions of terms such as solid waste, garbage, rubbish, household refuse, street refuse, dead animals, mixed paper, trash, solid waste, source reduction, reuse, recycling, recyclable, and residential solid waste can be found in the appendices and are provided as references.

The City of Gresham. The City of Gresham, population 68,237 as of 1992, administers its refuse collection program within its Department of Environmental Services and negotiates a five-year franchise agreement that allows an individual hauler to have exclusive rights to serve a specified route. Prior to 1983 , the ordinances that established the franchise system also established routes with few requirements. Currently, the ordinances that establish licenses with refuse collection haulers not only establish the routes but also establish the types of services that will be offered to residential customers within the City limits. Gresham's refuse collection system seeks to accomplish the following goals:

- License the solid waste collection and recycling services.

- Establish criteria for solid waste haulers.

- Provide education to the public.

Gresham has 10 firms licensed to collect refuse in 13 districts. Gresham has a uniform reporting system for the refuse collectors, and the information 
is used to establish rates for the haulers. Rates are established with the intent to insure that the haulers have a fair profit margin return and that all residents are served in the City. The rates are also used to encourage solid waste reduction and recycling practices. Gresham collectors use metropolitan disposal facilities regulated by Metro, a regional governmental entity. Recycling is an issue for the City and is reflected in local ordinance. The City adopted its latest ordinance for the operation of its refuse collection system in 1983, which became effective in January 1984.

The change from a franchise system to a license system established more regulation for haulers. The license system gives the hauler fewer property rights than does a franchise system. With this system, the City sets the rates, monitors consumer satisfaction, and establishes service standards for the City. Each garbage hauling company is charged a license fee, which is used to administer the refuse collection program. Recycling is offered to residential customers but is not mandatory. The City is not involved in the billing for refuse collection services. The garbage haulers send garbage bills directly to the residential customer.

Rather than adopt municipal refuse collection, the City of Gresham continued with routes that the garbage haulers had developed over the years. Gresham included the garbage haulers in the planning process as the service delivery system developed. In 1989, the City Council established districts for collection services and established that each district have one hauler for 
collection services. The City Council decided to have more than one hauler for the City so as not to create a monopoly. The City set up a maximum of 5 districts to produce the desired benefits for a comprehensive, unified, consistent, effective, efficient, and cost effective recycling program for the City.

The City of Beaverton. The City of Beaverton, population 53,310 as of 1992, has a license refuse collection system jointly administered by the Mayor's office and the Finance Department. Beaverton does not have fulltime employees in a separate department to manage the refuse collection system. Ordinances allow the City to grant licenses for services areas to garbage haulers. The garbage haulers should have a good service record, a good financial status, adequate equipment and personal capabilities to meet current City needs, and a good moral character related to collection. The objectives of the determination of need for the City of Beaverton as stated in Beaverton's code are:

- Provide the most effective service at the least cost.

- Avoid duplication of service.

- Reduce inefficiencies.

- Provide service to areas that are marginal in profit return.

- Improve opportunities for the license holder to make a reasonable profit, which will encourage investment in new equipment.

- Cooperate with the other governmental bodies.

Beaverton has had ordinances relating to refuse collection since the 
1970s. In 1980, the City adopted an ordinance to license garbage hauling companies. In 1990, the City passed another ordinance that established licenses and set service areas for the garbage haulers. Also in 1990, the rates were adjusted by resolution for the garbage hauling companies. City personnel in the Mayor's Office make recommendations to the City Council, and the City Council adopts the staff recommendations for amendments to ordinances.

Beaverton adopted a license for its refuse collection system so that all the garbage haulers would pay the same fee rate and meet the same standards. This eliminated the need for the City to negotiate separately with each hauler for service standards and rate structure. The license sets standards, rates, and routes for service, and it gives a single company exclusive rights to service, with a ten-year license, to service a particular geographical area. The license granted by Beaverton is given to one company to serve one area. The refuse collection system includes recycling, yard debris pickup, and other solid waste reduction programs to reduce the overall solid waste stream. A rate study is completed for the haulers as part of the rate setting process. Within the rate study, the City reviews customer satisfaction, customer complaints, and service levels. A recommendation is then given to the City Council for a rate level for haulers. Beaverton does include the garbage haulers in the planning process and in the rate setting process. 


\section{Conceptual Framework}

The conceptual framework for this study comes from Hans and Levine's writings (1984) on local politics and bureaucratic behavior and the work done by Stevens (1984), Ahlbrandt (1973), Savas (1977), Moe (1987), and Donahue (1987), all of whom have written about municipal service delivery and alternative organizational forms utilized for the delivery of refuse collection services. In these authors' investigations, questions were raised regarding the manner in which choices are made and regarding the efficiencies derived from an alternative service delivery mechanism utilized by local governments. Of particular interest to this study of three cities in Oregon is the decision-making process of local municipal governments and how local government makes policy decisions regarding alternative service delivery arrangements for refuse collection services. What follows is a survey of literature relevant to this study.

Moe (1987) has explored the concept of privatization and the limits that are inherent in this service arrangement. He has argued that there can be a combination of elements from the public and private sectors that can cause a shift in decision-making from local government to the court system. In short, the management of public services can end up being shifted from the managerial arena to the judicial arena because of legal questions. This is due to the lack of clarity regarding control, that is, whether the public or private sector has responsibility for services should problems arise. 
Ahlbrandt (1973) has concluded that more empirical work is required to substantiate some of the implied benefits of contracting any type of services. He has indicated, however, that contracting creates competitive market pressure that enables a community to get more services to its preferences and that contracting has lowered the costs of supply.

Savas (1982), in an analysis of the alternative arrangements for the delivery of services, has concluded that no arrangement is ideal when delivering services, whether the arrangement be market, franchise, voluntary, contract, grant, or voucher. Each of the service arrangements has positive features and negative features. Savas (1982) has concluded that "there is generally more than one good way to provide a service; it behooves one to recognize this when planning services and to select a delivery more on the basis of reason rather than reflex" (p. 87).

Stevens' (1984) comprehensive study examined organizational arrangements of service delivery for public works, public safety, support services, and parks and recreation that were either contracted out or provided by municipal government. The study addressed the question of organizational arrangement (contract and municipal) for service delivery and how organizational arrangements affected the cost of service delivery. The analysis of the study was to determine whether or not a generalization could be made about the relationship between organizational arrangement and the efficiency of service delivery. The Stevens study analyzed municipal solid 
waste collection for 20 different California cities. Ten cities had municipal refuse collection with public employees, and ten cities had contracts with private firms for refuse collection. Only those cities with once-a-week curb or alley refuse collection services were studied. For refuse collection, the study examined cost, scale of service, level of service, and quality of service delivered. Each of these variables was examined with regard to the technology for residential refuse collection, the organizational arrangement used for residential refuse collection, and the technology and management of residential refuse collection. Stevens (1984) has indicated that there are large cost differences between those services delivered by private contractors and those delivered by municipalities, and she makes the following observation: Given the very large differences in the cost of refuse collection which have been found, it is of obvious interest to attempt to discover what it is that private contractors are doing which enables them to deliver an equivalent quality service at a much lower cost than municipal agencies. (p. 171)

Overall, the research findings from the Stevens study indicate that on average refuse collection by a municipal agency is, on average, 28 to 42 percent more costly than refuse collection by a private contractor, and that low-cost (efficient) cities were more likely to use incentives and have their workers go home when the rcute was completed.

Donahue (1989) has stated that garbage collection is perhaps one of the 
best ways to compare private and public efficiency in public service delivery and that "the most ambitious appraisal of alternative organizational arrangements for garbage collection--at least in the United States--was done by Barbara J. Stevens" (p. 63). Donahue (1989) has also reported that "there is considerable evidence that competition, rather than organizational form, is the crucial factor in efficient trash collection" (p. 67).

The design of this study of alternative municipal service delivery and organizational arrangements in the delivery of refuse collection services has been influenced and given direction by the writings of the above authors. The focus of the writings of these authors is on politics and decision-making, privatization, contracting out services, and rationales for the selection of alternative services. Savas' notion that a service delivery can be selected on the basis of more than one reason, is of particular importance to this study. The management technology variables from Stevens were used as a model to explore whether refuse collection systems in Portland, Gresham, and Beaverton have the same characteristics found in her study. The study by Stevens is important because it is the model for this examination of the operation of refuse collection services as a arrangements for the delivery of refuse collection services.

Purpose

This study intends to contribute to the discussion on the choice of alternative service delivery arrangements for the delivery of municipal 
services, using residential refuse collection as the substantive service area. The purpose of this study is to examine how government makes decisions about residential refuse collection services and to examine the bureaucratic behavior of government in the choice of private organizational arrangements for the provision of public services. In addressing the policy question of service delivery through public or private means and also those factors which determine the choice for the selection of a service delivery arrangement, the literature has explored both monetary and nonmonetary factors in relation to choice in service delivery. This study focuses on the role of nonmonetary factors in the choice of alternative service delivery arrangements for residential refuse collection.

This will be accomplished through a qualitative examination of government service delivery in the collection and disposal of refuse from residential homes by private firms in the cities of Portland and Gresham (in Multnomah County) and Beaverton (in Washington County), all in the State of Oregon. Both private haulers and public officials are included. For the purposes of this study, refuse collection is defined as the pickup and removal of refuse collected from residential homes, which includes mixed household waste, yard debris, and other miscellaneous items, for disposal.

The study will examine the stability and the regularity of use of private arrangements by government agencies and seeks to determine what accounts for differences in the types of arrangements chosen in different jurisdictions 
within the same metropolitan area. Management technologies are explored to determine their effects on service delivery and to ascertain whether the three cities have the sarne characteristics found in the Stevens study. If the characteristics are found not to be the same, then the differences that are unique to these cities will be explored. The study will characterize efforts to make changes and characterize how changes have been instituted. Further, the relationships that cause pressure for change will be examined in order to compare how political cultures lead to different organizational arrangements.

The literature provides numerous studies that examine municipal services, using such variables as salaries and material costs of services, in an attempt to determine where efficiencies exist in municipal services. This study will explore how certain empirical regularities exist in Portland, Gresham, and Beaverton and how these regularities came to be. This will be accomplished through an exploration of the history of the development of refuse collection in Portland, Gresham, and Beaverton.

Understanding how certain regularities exist across jurisdictions for the types of organizational arrangements is important for two reasons. First, the information can help clarify the planning process for choice in the type of service arrangement a particular government jurisdiction can adopt, and second, the information $\mid$ can help managers understand those nonmonetary factors present when government makes decisions about service arrangements. 


\section{Summary}

This chapter begins with a survey of the history of garbage collection from the early periods when disposal of unwanted materials was simply to dump it into nearby land. As civilization advanced the problems of waste accumulation increased and social systems developed legal mechanisms to structure the process of disposal. A centralized location (landfill) became the place where unwanted material was taken. After years of dumping at landfills, there was a realization that negative consequences had occurred and different options were needed to effectively manage garbage and its disposal. There have been concerns that landfills are filling up and concerns about the types of materials going into landfills. The problems of garbage collection and disposal are were found to be complex with no easy answers. A crisis became evident as solutions were sought regarding how to manage the accumulation of garbage and the ultimate disposal of the garbage. Government have used various methods to collect garbage which included municipal collection and various forms of private collection. Government acted by passing law at the federal level which stimulated change at the state and local level. Portland, Gresham, and Beaverton made changes in the residential refuse collection systems operating in those cities in response to mandates to reduce the amount of solid waste entering the waste stream.

In this chapter, the discussion of changes in refuse collection has focused on the waste disposal crisis, the decisions being made that stimulate 
proposals for change, the responses to factors that create pressures for change, and the relationship between private haulers and the political characteristics that cause pressures for change and lead to the development of different arrangements in response to change. The chapter closes with information from the literature that has influenced and given direction to this study of residential refuse collection in Portland, Gresham, and Beaverton.

The purpose of the study is to examine how government makes decisions about residential refuse collection services and to examine the bureaucratic behavior of government in the choice of private organizational arrangements for the provision of public services. 


\section{Chapter 2}

\section{SERVICE ARRANGEMENTS IN U.S. CITIES}

\section{Introduction}

Historically, the Portland metropolitan area did not develop municipal sanitation departments for residential refuse collection in the same way as other cities around the country. Therefore, a review from the literature on other service arrangements is included in this chapter so that municipal refuse collection can be presented along with the service arrangements of the cities under study. Because the three studied do not have public collection, a review of municipal refuse collection will give additional information and add perspective to the different types of service arrangements not available in Portland, Gresham, or Beaverton.

The Institute for Solid Waste of American Public Works Association (1970) has reported that refuse collection and disposal functions were assigned to public works or public service departments in about 60 percent of U.S. cities. About 20 percent of these refuse collection and disposal functions were located in sanitation departments, 5 percent in engineering departments, and 10 percent in various other departments. Other non-specific arrangements account for the difference, the remaining 5 percent. Where the function of refuse collection was located within the municipality depended on the size of the municipality and traditional arrangements. Planning activities were done on a citywide basis while immediate aspects of refuse collection and 
disposal were done at the departmental level. Refuse collection planning and management services were performed within the department and could include such activities as equipment purchasing, equipment maintenance, accounting, operations maintenance, and report preparation.

The size of the municipality, the patterns of planning, disposal sites, and overall planning have appeared to determine how refuse activities are carried out. There are many types and combinations of collection vehicles, crew size, frequency of collection, work scheduling, and routing used in various municipalities (Wilson 1977). The condition of the topography determines the best possible routes and scheduling procedures for a crew. Density and housing mix also affect how residential refuse collection services are delivered in a municipality. The size of the crew depends on the overall system, equipment, and the types of services offered. Crew scheduling is a choice between a fixed hour system and a schedule wherein the crew members can leave work once the work is completed. This latter is called a work incentive system. Types of services include frequency of collection and location where the collection will occur.

While many of the organizational arrangements used are not pure in form, the major types of arrangements are municipal collection (public), contracting out (private), franchise (private monopoly), non-franchise (private), and license (private). A major difference between the contracted refuse collectors and the franchised collectors is that the contracted refuse 
collectors are paid by the city for their services, and the franchise refuse collectors bill the residential household directly for their services. Those operating under a non-franchise private organizational arrangement also bill the residential household directly for their services (Stevens, 1984).

Public collection of refuse from residential homes has been a significant cost of municipal budgets. Comparisons have been made to determine the efficiency of public refuse collection versus private refuse collection for many U.S. cities (Stevens, 1984). Wolf (1988) and Donahue (1989) have provided information that delineates evidence both for and against the efficiency notion because: Depending on the municipality, the data and the results will be different. For 53 cities and municipalities in the St. Louis County area (Missouri) there was no significant cost difference between public and private collection. However, the cost of public services was 40 to 60 percent higher than private services in many other U.S. cities when comparing municipal services to private monopoly franchise firms (Wolf, 1988). Wolf (1988) has also cited a study that showed 101 Connecticut cities with private monopoly contracts and private non-franchise firms versus municipal firms (i.e., public collection) and found that costs were 14 to 43 percent higher than contract costs. Nonfranchise firms had a 25 to 36 percent higher cost than municipal collection services. Many U.S. municipalities have entered into contracts for refuse collection services, and many have used franchising as an option for refuse collection services. The 
major difference between contracting and franchising is that the contractor bills the municipality for the services provided, and the franchise operator bills the residential customer directly.

Many cities in the United States use tax financing to provide refuse collection services using municipal employees. Other U.S. cities have user charge systems to finance refuse collection services. Municipalities such as Ontario, California, and New York, New York, developed municipal service arrangement options for service delivery. Private service delivery options were developed in municipal jurisdictions such as San Clemente and Costa Mesa, California. These two cities had contracts with the private sector to deliver refuse collection services. Phoenix, Arizona, divided the city into four sectors. Two sectors were reserved for the city's municipal sanitation division and two sectors were placed out to bid. The two sectors reserved for the city sanitation division werel to ensure some local capacity for garbage collection (Donahue, 1989). In his explanation for the division of Phoenix into sectors, Donahue has suggested a need for open competition to ensure that there is a high quality of service delivery and, further, suggests that open competition is the most efficient form of garbage collection service. Other factors mentioned by Donahue (1989) that could have accounted for the choice to section Phoenix was the illicit collusion, or traditions, established in local jurisdictions. Donahue's example of Phoenix illustrates decision- 
making based on the need to meet political agendas and not necessarily on cost alone.

Savas (1982) has indicated that government uses contract agreements to purchase outright most supplies and equipment. Donahue (1989) has shown that two-thirds of all American cities have some type of private trash collection, either in the form of free competition among firms or in some other form of franchise or contractual agreement with a government agency. Also, 45 percent of the cities have only private firms, and 33 percent have public collection systems operating as a monopoly.

\section{Service Arrangements: Municipal Collection}

Within the framework of a municipal service arrangement, the government agency arranges for a service and then produces the service for the consumer. A government service is defined as: the delivery of a service by a government agency using government employees (Savas, 1982). A municipal refuse collection system has public employees and is routinely located within the public works department. The municipal government usually owns and maintains the equipment used for the delivery of the refuse collection services and also determines the scale of operation, the type and level of services, and the management practices that will be used. Public employees may also be union employees, which affects salary structure, benefits, and actual work practices.

In many U.S. cities, public collection developed as the primary service 
delivery option for the pick up and disposal of refuse from residential homes. According to a report by the Bureau of Governmental Research and Service, University of Oregon (1988), there was a common practice in many U.S. cities to operate universal refuse collection services using public employees and financing the operation with tax dollars. Services offered to residents were either tax supported services or assessed a user charge. For universal services that involved user charges, all who utilized the services were required to pay the charges. There has been a shift from a tax financed system to a user financed system in those cities that had a tradition of universal service. In Oregon, most cities limit the involvement of regulation to the private collection system. Of the cities surveyed in a study by the University of Oregon (1988), common practices for refuse collection were in three categories. One category was the unregulated system, such as that found in Boulder, Colorado, and in St. Paul, Minnesota. These two cities were like Portland, Oregon, prior to the 1992 implementation of its regulated program. Before 1992, Portland had a private open competitive refuse collection system. The second category was that of universal usage with a tax financed municipal collection system, which eight cities utilized. The third category was that of user charges where the city billed the residents. Two cities had user charges with service arrangement and the city billed residents. Public collection offered by municipal governments consists primarily of the same type and level of services as did private service arrangements. 
While the actual pickup and delivery of refuse collection appears to be about the same around the country, there are some differences between municipal collection systems and private collection systems. Donahue (1984) has indicated that public and private collection may not be the same product. Management practices, labor unions, and financing mechanisms are examples of what can make residential refuse collection different product when the actual pickup and disposal of refuse is the same task. Municipal refuse collection as a service delivery option has been shown to be a significant part of municipal budgets. Labor negotiations with unions become an issue as part of municipal services, which directly affects the cost of the delivery of municipal garbage collection. When work is of a poor quality, it can become difficult to dismiss workers for low quality work, and worker's pay may be linked with other powerful unions. Management requirements may be based on other government mandates; this can create multiple layers of management. In many cases and for various reasons, municipalities can have refuse collection systems where competition is not present. Municipal refuse collection systems can have mandated services with requirements for citizen coproduction. Coproduction may require that the resident transport the household garbage to the curbside.

The University of Oregon report (1988) has indicated that private garbage hauling companies have been established in U.S. cities for many years and that cities have had varying levels of municipal regulation. Beaverton 
has operated with a franchise agreement, and Gresham has regulations that establish operating territories for garbage collectors. Service arrangement options for Portland, Gresham, and Beaverton have never included municipal residential refuse collection, and municipal residential refuse collection as a service delivery option has not been seriously considered an any of these jurisdictions.

The development of service arrangements in the three cities under study has evolved in a manner to meet the needs of local communities. Portland, Gresham, and Beaverton each developed different options for refuse collection to meet specific needs or to serve a purpose for the community in the overall strategy for service delivery. In the local jurisdictions, as in other municipalities, policies were developed to preserve traditional service providers and to incorporate new demands from external sources to stay in compliance with new administrative rules and laws, Service Arrangements: Portland, Gresham, Beaverton

Table 1, below, displays the types of service arrangements in each of the three cities. There are some common features not only in the types of service arrangement options chosen by each of the cities but also in the decision making process, that is, the reasons for these choices. Within each of the municipal governments, there has been the belief that municipal collection would be too costly to implement, that private garbage haulers do a better job, and that no one wanted to put private garbage haulers out of business. The 
task was to structure an arrangement that would require private haulers to comply with a system designed to meet new state mandates, while also giving consideration to alternative forms of refuse collection systems in order to maximize solid waste reduction, increase recycling, and maintain the integrity of the existing garbage collection system. For Portland, one option was the continuation of the open unregulated residential refuse collection system. In addition, Portland, Gresham, and Beaverton all had the option to contract with one or two garbage haulers for residential refuse collection or to franchise/license local haulers for residential refuse collection services. All the three cities chose to continue with current haulers when changes were adopted in ordinances. The three cities have maintained small bureaucracies to manage the refuse collection system.

Table 1

Service Arrangements

\begin{tabular}{lll}
\hline Jurisdiction & Service Providers & Arrangement
\end{tabular}

City of Portiand

Private businesses

Franchise - nonexclusive

City of Beaverton

Private businesses

License - exclusive

City of Gresham

Private businesses

License - exclusive 
While organizational arrangements used in the three cities have different titles (e.g., franchise versus license) these arrangements function virtually in the same manner.

The process for evaluating refuse haulers could be considered to be complaint driven inasmuch as an evaluation and/or review occurs only when customers have problems with a hauler. While Portland, Gresham, and Beaverton provide a prescribed level of services, customers determine the level of service desired (i.e., size of the can and the frequency of pick up). Each of the three cities has maintained and continues to maintain ordinances with the standards and programs as service options for residential customers. The cities regulate the types of services to be delivered to the customer, such as recycling and yard debris disposal. Each of the three cities sets the rates that the haulers will charge the residential customer and determines the fee schedule to be paid to the jurisdiction. The three cities work with haulers through the rate structure to assure that haulers have a reasonable, profitable return. Each city reviews the financial records of haulers to determine whether the hauler has a loss or profit. Should the hauler be in a nonprofitable position, the city adjusts the rate to assure profitability. Correspondingly, should the hauler make too much profit, the city adjusts the rate structure to assure the customer is not being overcharged. Haulers bill the residential customers directly. 


\section{Summary}

Municipal collection did not develop as a service arrangement in the Portland metropolitan area as it did in other U.S. cities. Refuse collection has been a significant part of municipal budgets and has been financed by a variety of methods. One difference between municipal refuse collection and private refuse collection is the billing arrangement with the citizen. Many organizational arrangements used for the delivery of refuse collection services are not pure in form and may consist of elements of both the private and public sectors. Also, cities have implemented refuse collection services that would specifically meet the needs of the citizens. Municipal refuse collection is a refuse collection service that is delivered with public employees and financed with some form of government financing mechanism. There are some common features of the service arrangements in Portland, Gresham, and Beaverton. There has been the belief that private haulers would deliver residential refuse collection services at a cost lower than a municipal residential refuse collection service as well as do a better job. There was also a desire by public officials to not put the private garbage haulers out of business. The cities regulate rates charged to the haulers and the residential customers through a rate setting process. Under the service arrangement, cities are not involved with billing residents for residential refuse collection services. The garbage haulers bill the resident directly. 


\section{Chapter 3}

\section{REVIEW OF THE LITERATURE}

\section{Qverview}

Refuse collection (also referred to as garbage collection) is a basic municipal service that has received considerable attention in the literature. This literature review explores refuse collection as a municipal service and includes information from the fields of Public Choice and Urban Policy Analysis. Additional literature has been reviewed from Public Administration to further the discussion about options for alternative arrangements.

In the Public Choice literature, refuse collection services, along with other municipal services such as fire protection and school bus transportation, have been investigated by such individuals as Ahlbrandt (1973) and Zardkoohi and Giroux (1990). Refuse collection has received considerable attention regarding the policy questions of efficiency, utility, and decision-making for refuse collection services. Also, as a policy question, the literature on refuse collection service raises issues about choices in strategy for the delivery of service and about the means (public or private) through which should refuse collection should be delivered. Discussion in these areas takes the following form:

- 1 The market is a better choice for delivery of refuse collection services than government. 
- 2 Markets are more efficient than government in delivering the same service.

- 3 Market production and public production may not be the same.

Researchers in the field of Public Choice such as Savas (1977 \& 1978), Stevens (1984), Wolf (1988), and Donahue (1989) have explored from different perspectives the theoretical and practical applications of alternative services arrangements as related to the policy questions of cost, effeciencies, and those factors such as labor negotiations that go into decision-making for the choice of service arrangement for a municipality. Public Choice, as a body of literature, studies non-market decision-making. Public Choice takes the tools of economics and applies them to the materials of politics, through a process of deductive reasoning, in order to understand what decisions might be made in order to maximize choices (McLean, 1987). The information on managerial behavior from Public Choice literature has been added to bring focus to the study of private firm managers and government agency bureaucrats.

One underlying rationale for government use of private organizational arrangements is the general belief that private organizational arrangements are more efficient and less costly than municipal agency delivery of the same service. Within this framework of less cost and more productivity through the use of private institutional arrangements, Wolf (1988) has suggested that the competitive marketplace produces goods and services more efficiently 
than the public counterpart. There has also been an argument that monopolies, whether public or private, tend to be inefficient and more costly. Donahue (1989) has provided evidence that both open competition and monopolistic private franchises for garbage collection often are inefficient and that contractors typically outperform their public counterpart when the bidding competition is fair and honest. Hatry (1983), in discussing new approaches to the delivery of government services through private sector participation, has indicated that alternative approaches can have the effect of lowering costs, reducing the demand for services, reducing government services, raising more revenues for government services, and increasing the amount, quality, and/or effectiveness of a given government service.

The search for efficiency as demonstrated in the literature by the Stevens (1984) study of public and private refuse collection, has been made in the area of comparison of cost for delivery of the same services under the same conditions. Analysis of the cost to deliver similar refuse collection services under similar conditions by such researchers as Stevens (1984) and Pack (1990) has led to different conclusions. This is due to such factors as accounting differences among various jurisdictions, the manner in which tax codes affect the cost of services to the consumer, the economies of scale between operations which include both private and public, the distance to the landfill, the frequency of pickup of refuse, and the type of organizational forms used within a geographic area. Municipal service policy questions of 
equity and accountability have also been explored by Donahue (1989). The questions he raises: Who profits, how do certain institutional arrangements affect cost and delivery, and how does the public benefits.

Literature from Urban Policy Analysis brings to this discussion a focus on the underlying concepts to understand ideas of bureaucratic behavior and service delivery to add perspective to the phenomena occuring in each of the three cities. Clark (1985) writes about Urban Policy Analysis from a systems perspective and talks about how four subfields within Urban Policy Analysis influence each other. He has indicated that political leaders and citizens influence bureaucratic processes and service delivery, which in turn influence population and employment patterns. The population and employment then influences citizens and political leaders. Clark (1985) has stressesed that it is the interrelated processes that form the core of policy analysis. As such, more than one theoretical framework from the fields of public choice and public policy have been used to discuss the context in which refuse collection operates as a municipal service. Using the systems perspective of viewing more than one theory can allow for other processes to have impact on policy questions. Clark (1985) has presented two theories from a contextual framework within Urban Policy Analysis in relation to bureaucratic processes and service delivery. One theory is that of incrementalism and the other is contextual characteristics affecting service delivery. Incremental theory as advanced by Clark is the belief that 
bureaucrats do the same functions year after year and make small changes. Policy makers seek, in the context of Incrementalism, to deal with each new problem as it arrives and in this way create policy. In the case of the contextual characteristics affecting service delivery theory, factors such as unions are seen as influencing services in the decision-making process. For example, contracting for services is an option for bureaucrats and may or may not be used. However, contracting is an option that can be used and, in that context, can influence bargaining for service delivery.

Savas (1984) has identified nine different alternative service delivery models that are used by municipal governments in the U.S. used by governmental bodies such as mail service and lending institutions, these service delivery models include: government service, intergovernmental agreement, contract or purchase of service, franchise, grant, voucher, free market, voluntary service, and self-service. Alternative methods for the delivery of services (e.g., refuse collection and fire services) include contracting, franchises, grants and subsidies, vouchers, volunteerism, selfhelp programs, tax policies and regulations, reducing the demand for service, obtaining temporary help from the private sector, and using fee structures for individual services. The alternative collections options for waste management and disposal in U.S. cities are as follows:

-Municipal service with public employees--monopoly

- Private contract, contractors bill the jurisdiction--competitive 
-Private franchise--monopoly

-Private franchise--competitive

- Private license--monopoly

-Private--open competition

Each of these options may be desirable under certain circumstances.

There is no clear consensus in the literature as to which policy option is best. However, evidence in the literature does suggest that choices are often based on factors other than cost, efficiency, or public law. In some communities the choice for the use of private enterprises to provide refuse collection services has been made by tradition, while in other communities the choice for the use of private arrangements has been made in an effort to reduce costs (Geshowitz, 1971).

\section{Municipal Services and Private Arrangements}

Public choice theory has played a key role in the analysis of alternative arrangements for public service systems organization (Ostrom \& Bish, 1977). The utility of a particular service arrangement for a municipality has been explored from the contextual frameworks of policy and politics and decisionmaking. Alternative service delivery arrangements, as the unit of analysis for study within the context of public goods, has generated discussion in the areas of problems associated with the delivey of refuse collection services and policy implications that might be derived from any alternative production arrangements. Thus, research and dialog on municipal services and private 
arrangements have made clear some of the advantanges and disadvantages within alternative choices for municipal service delivery. For example, there are clear advantanges for government to provide fire protection services for citizens and a clear disadvantage in some service arrangements is the lack of readily definable tasks that can be measured and evaluated. Discussion in the area of Public Choice theory also addresses bureaucratic behavior in decisionmaking related to the utility of a service and possible positive impact of government policy options.

The study of the characteristics of alternative arrangements for the delivery of public services and the choices made has been done to clarify distinctions between service delivery modes. A service produced by one type of organizational form may not be the same when produced by another organizational form. For example, refuse collection services may not be the same service when delivered by a municipal government as when delivered by a private firm. What makes the service different may lie in the tasks necessary to carry out the function. The literature focuses on alternative service delivery modes in the area of measuring efficiencies in terms of cost, management, quality, and frequency of the service delivered. Also, the use of such alternative arrangements as privatization, contracting out, and monopoly (franchise or license), as opposed to public delivery of services, has been examined for evidence that supports or rejects theoretical arguments for and against public service delivery. 
Examples of valid arguments based both on philosophy (tradition) and economics (i.e., taxing policies) have been presented in the literature by Savas (1977) and Wolf (1988), who discuss the issues of privatizing certain segments of government services. Savas (1982) makes the following statement in summarizing the discussion regarding the positive and negative features of various service arrangements:

The arrangements differ substantially with respect to this array of important attributes, and no arrangement is ideal. Each has many positive features and lacks others. Many arrangements share each desirable feature. The conclusion to be drawn is that there is generally more than one good way to provide a service; it behooves one to recognize this when planning services and to select a delivery mode on the basis of reason rather than reflex. (p. 87)

The positive aspects presented in the literature tend to focus on how the private provision of services will actually enhance the provision of services rather than burden an already expansive and large bureaucracy. The assumption is that the private provision of government services will improve efficiency and accountability, as well as reduce cost. A large body of evidence in the literature supports the assumption that the real cost of public supply is higher than that of private supply for the same quantity and quality of service (Hanke, 1983). It is believed that private firms use fewer resources to produce the same services as public firms. A negative aspect of the use of 
private arrangements to carry out public services is the inability to be able to define tasks for some services, as Donahue (1989) noted and the tendency to support the concept of turning over all government functions to the private sector.

In the context of service delivery options, the question of efficiency has been central whenever comparisons are made between public and private agency performance and when considering the types of private arrangements used by government to deliver services. Because of the complexities of individual service arrangements and the issues of both performance and cost to deliver a municipal service, the choice of arrangement continues to be an empirical question open for investigation. That is to say, theoretical questions will have to be addressed continually in order to answer questions in each contextual framework of bureaucratic choice. This is because a particular service may not lend itself to delivery by one type of arrangement and a combination of arrangements may need to be used.

As municipal governments have increasingly used varying forms of privatized institutional arrangements to achieve public goals, the line between private and public has become indistinct (Moe and Stanton, 1989). Hula (1986), Morrison (1989), and Rein and Rainwater (1989) also provide information on the public/private interplay between government and private enterprise and suggest that there is a shift in responsibility from government to private enterprise. Because of the complexities involved with 
the private delivery of public services (i.e., legal requirements meant for public employees), sectorial blurring becomes part of the discussion of privatization and public needs. An example is the use of the private sector to provide correctional institutions. Because the private sector has played a role in the provision of such services as correctional institutions, questions of responsibility, cost, and efficiency for the public and private sectors has been debated around the issue of roles and responsibilities. These issues create problems around the legal interpretation of laws and regulations meant for public employees but not for private employees.

Arguments have been made in the literature that privatization is imprecise. This can be seen in the nature of the organizational structure and the relationship of the arrangement to public entities. An organization is considered imprecise when the legal structure is private but the organization is attached to a public entity and receives public funding. An example of how privatization is imprecise can be seen in the legal organizational structure of the United States Postal Service: The Postal Service is a mixture of both public institution and private enterprise.

Whether the delivery of services is public, private, or a mixture of the two, the evidence for relative efficiency of public versus private organizational arrangements, performing similar tasks, is not clear. Furthermore, the differences are often subtle and complex (Donahue, 1989). Therefore, the main criterion for choice in selecting alternative delivery 
options should be the nature of the task and how the task will be accomplished. There are problems inherent in each type of organizational arrangement used. For example, the private organization may have profit as a motive and therefore will allow the profit motive to direct organizational behavior. One problem with public sector service delivery is that tax mechanisms are often used to pay for delivery of services, so obtaining a true cost for services may prove impossible. Because of problems such as this, the range of considerations for choice should include intangible qualities, such as tradition and experience, along with a measurement for efficiency and equity. While the use of private organizational arrangements has been presented as less costly and higher in quality, the choice for public or private arrangements stems from different kinds of tasks, which leads to different types of relationships. The contracted service or privatized operation has been shown to be higher in quality because a municipality can set minimum standards for the public service and does not have to pay for the service delivered should the standards not be met. With municipal service delivery, unions and labor agreements may prevent intervention to insure quality service levels, should minimum standards not be met, which can lead to higher costs.

The proof for evidence of efficiency in the service delivery arrangement rests mostly with where the evidence is presented. Donahue (1989) has indicated that the distinctions are not clear enough for a fair 
comparison of public and private efficiencies. Problems in the real world create the necessity for analysts to operationalize definitions of "private," "public," and "efficiency" in order to allow for a fair comparison. The operationalized definitions can then account for factors aside from publicness and privateness when setting out evidence on the relative efficiency of public and private organizations performing the same tasks. Donahue (1989) goes on to say that in the real world there could be other factors (e.g., politics) that may enter into the ideological arguments and, thus, enters into the equation regarding choice of the type of service delivery arrangement. An example of this is the experience of Phoenix, Arizona, where the city was divided into quadrants to provide refuse collection services as a way to meet local needs. The decision to divide the city into quadrants was based on the politics to meet specific local demands.

There are many policy considerations to keep at the forefront of the planning process when making policy decisions about service arrangement options. As Wolf (1988) has shown, there are many choices to be made between imperfect alternatives, especially when those imperfect alternatives are not always clear choices. The results of such comparison between alternative choices often depend more on the views and the philosophy of the evaluators than on their analyses. It is extremely difficult to make comparisons between market and nonmarket alternative service delivery systems, especially, as Wolf (1988) has stated, " because there is no general 
applicable formula for choosing between choices" (p. 115). The comparison of market and nonmarket alternative provisions of government services are prone to shortcomings and the preconceived notions of those making the comparison. It is conceivable that there are many flaws in any option chosen to deliver a municipal service and that the desired outcomes may not be attainable, through any service arrangement option chosen. The desired outcome may in fact be attainable yet the predictability for achieving the desired outcome may be unattainable. Political climate, social histories, and economic conditions add to the mix which creates the inability to correctly predict a service arrangement.

Basic choices for service delivery arrangements are that government can either provide a service with its own employees or provide the service through some another agent with some form of contractual arrangement. The choice between private service and public service delivery, as Wolf (1988) has pointed out, could be considered a matter of emphasis and degrees. The differences between alternative choices may or may not have an effect on the performance of a service and how equitable that service can be for citizens. A look at the options chosen by government for the implementation of alternative service options has stimulated discussion regarding choice in service delivery. These discussions have led to more information being available to help with decision-making and have led to a greater 
understanding of the outcomes that a government policy option can have on the urban community.

The outcome of municipal service delivery systems, where private arrangements have been used by local governments to deliver services, is contained in specific research studies and literature on the role private arrangements have had in municipal services delivery. Contributors to the the literature in this area include Savas (1977), Ahlbrandt (1973), Hahn and Levine (1984), and Rein and Rainwater (1970). The Stevens study (1984) investigated the relationship between organizational arrangements and efficiency in the deliveryof municipal services in 20 cities. Cases where government has used private organizational arrangements to achieve government aims are also seen in municipal fire protection services (Ahlbrandt, 1973). Another illustration of the use of private organizational arrangements by government is refuse collection services in many U.S. cities. The U.S. Department of Housing and Urban Development (1987) has reported on local partnership projects in communities across the U.S. where various organizational forms and strategies were used to implement a desired task for the community. In one example, Martin Rein (1970) has indicated that urban renewal was the public policy within which private industry was used to meet housing needs. Another instance of the use of privatization to deliver public services is the Wastewater Privatization Project in Auburn, Alabama. In this project, the city's wastewater treatment facilities that were privatized 
because a study showed that updating the plant was not financially feasible for the city. Based on the results of the study, the city decided to privatize the system. The use of a private organizational form to meet the wastewater needs of the city worked. A preference for private action and the insistence on competition through a bidding process is seen in federal contracting regulations and in state and local laws. In Oregon for example, the Oregon Revised Statutes, ORS 279.011 to ORS 279.063 have created contracting policy and established the competitive bidding process. Local municipal governments in Oregon have adopted policies with the legal sanction of State Statutes to achieve the policies of local government.

Writing in the area of Public Administration, Barry Bozeman (1988) has outlined the limits of using private iorganizational arrangements for the delivery of public services. He has stated that, while private organizations are very different from public organizations, it would seem that almost any government service can be turned over to the private sector. There are costs to privatization, of course, and realistic judgements must be made about which market mechanism will work best to meet the policy goals. Bozeman (1988) has postulated in theory that research can inform planners and others as to which structures would perform well for which particular sets of public problems. Policy planners are likely to find that in some cases policy objectives are better served by the market, and in other cases, policy objectives may be better served by government agencies. The quality of service does not 
appear to be tied to either public provision of services or the private provision of services. Rather, either position can be argued as being the best alternative choice for service delivery.

The literaturel does not offer a clear delineation of choices between government and private provision of services. However, as mentioned earlier, there is a belief that the competitive process within the private sector will reduce cost and provide a higher quality service (Newman, 1968)! While there is the common belief that cost is the overriding factor that determines choices in service alternatives, the literature does not conclusively point in that direction.

Bureaucratic Behavior

Contracting out services has received considerably more attention in the literature in recent years because of what Elliott and Ali (1988) have seen as a heavy reliance by municipalities on the use of private arrangements to formulate and implement major urban decisions. The authors have also stated that the increase in contracting has given rise to a new industry. Dunleavy (1986) has taken a strict approach to privatization and contracting out as a means of public service production and argues that there has been a permanent transference of service or goods which, while once previously carried out by government, are now carried out by non-public organizations. Dunleavy has suggested that this concept is a continuation of bureaucratic 
behavior (i.e., strategies), one already developed by senior policy level bureaucrats to advance their interests.

Within Urban Policy Analysis, theories of bureaucracy and managerial behavior, and those characteristics that affect service delivery can provide an understanding of the context in which decisions are made and how labor unions and contracting affect policy decisions, which in turn elffect service delivery (Clark, 1985). The theory of incrementalism would suggest that bureaucratic behavior will be the same when planning for services and that changes in the services will be made as minor adjustments each year. The incremental theory predicts small changes over a period of years.

Another important focus on bureaucratic behavior from Public Choice literature has been with the choice of inputs. Whether bureaucrats will exercise their option to expand or not expand will depend on the constraints placed on their behavior. According to Zardkoohi and Giroux (1990) the theory of managerial behavior is split into the study of the behavior of private firm managers and that of government agency bureaucrats. It is these authors' postulation that managers and bureaucrats may attempt to maximize their utility at the cost of their employers and that private firm managers have more constraints than bureaucrats. They begin their discussion with one assertation that government agencies have incentives to oiveremploy capital as opposed to labor. They argue that the budget minded bureaucrat wants to engage in projects that have greater gains in a short time period 
rather than to engage in projects that have smaller gains in a short time period, thus having to wait for the larger gains over a greater period of time. Another hypothesis is that an oversized staff is a source of gain for politicians and bureaucrats. These authors have indicated that Tollock (1965) has suggested that government agencies have incentives to increase the size of their staff because of the benefits that are accrued in favor of political incumbents.

Zardkoohi and Giroux (1990) have empirically examined the behavior of government bureaucrats in relation to the choice of labor and the latitude given to the bureaucrat. Latitude was defined as the degree of freedom a bureaucrat had to behave opportunistically. In this case, latitude was in the area of choices regarding service option for the delivery of a specified type of service. These authors, following work previously done in the field, hypothesized that government agencies have a preference for oversized staff. They looked at the ability of the bureaucrat to behave opportunisitically based on the controls placed on them by other government mechanisms, such as the city budget and intergovernmental agreements. Zardkoohi and Giroux's (1990) examination replicated research studies on municipal governments using standard regression procedures to examine government, bureaucratic behavior, the production of service with such variables as audit, measures of fiscal complexity, ratio of intergovernmental grants to total city revenue, per capita income, and total budget of the city. The results (Zardkoohi and Giroux 
1990) showed general support for the hypothesis that there was a preference to overstaff and that the bureaucratic desire was limited only by the degree of cost to monitor a bureaucratic behavior. Bureaucratic choice is then reflected in the degree of monitoring, whether by taxing complexities or some other complexities.

McGuire, Ohsfeldt, and Van Cott (1987) have noted in Public Choice literature that little formal analysis of the bureaucratic choices of production modes has been presented. These authors have stated that the large body of literature developed over the last two decades compares the performance of the public sector economic activity with that of the private sector. The hypothesis is that private firms are more efficient by market standards because the rewards and costs of production reside with the owners of the resources and they are involved in production to a greater degree than managers of public firms. While the work by these authors generally confirmed their hypothesis, the authors have noticed that the literature fails to explain why there is a persistence of public production of services when extensive evidence exists to support the superiority of private sector performance. In the end, they have posed an excellent question: Why do some governmental bodies choose to provide a publicly funded service with publicly owned and operated production units while other governmental jurisdictions make service arrangements with private firms? As restated as a part of the purpose of this study, the question reads like this: How does 
government make choices in service delivery arrangements for the delivery of refuse collection services?

\section{Decision-making}

Overall, decision makers appear to have been more responsive to nonmonetary constraints than to changes in monetary constraints. McGuire, Ohsfeldt, and Van Cott (1990) have analyzed the nonmonetary factors of relative strike, spending proclivities, and tax proclivities to examine how responsive decision makers are to monetary and nonmonetary constraints. These authors have concluded that the importance of nonmonetary considerations suggests that it is unreasonable to expect public sector choices to be affected by evidence of the cost inefficiency of public production. In the areas of contracting for service delivery, for example, the literature has focused on efficiency results and not on the process of decision-making. Pack (1990) has offered an opposing view to the conclusion drawn by McGuire, Ohsfeldt, and Van Cott. In her own study, Pack (1990) has concluded that more work is needed on economies of scale (in this case more study on school bus transportation) before any conclusion can be reached about the importance of monetary and nonmonetary factors in contracting decisions. The differences in the conclusions drawn by Pack's (1990) research and the research by McGuire, Ohsfeldt, and Van Cott (1987) indicate a need for continued theoretical and empirical analysis to make better inferences about the nature of the bureaucratic choice. More understanding about incentives, 
structures, and relationships is necessary to bridge the gap between constraints and choice for the use of various service delivery alternatives. Decisions are not made in a vacuum. Decisions are made as a result of political and bureaucratic pressures (DeHoog, 1984). Other factors, such as labor unions and contract law, also need to be taken into consideration by bureaucrats when policy options are considered.

The evidence in the literature gives every indication that the line which separates public and private is not clear and that this line shifts from decision to decision. Donahue (1989) has indicated that municipal governments are more likely to use a private option for service delivery when a task is clearly defined, service production can be clearly measured, and the service can be easily terminated with minimal disruption. Conversely, al municipal government is more likely to develop a municipal service (hire employees) when the task is unclear and can shift from time to time, measurement is difficult due to rapid changes in production outputs and non-production outputs, and termination of the service would cause undue hardship for those to whom the service is being delivered.

While authorities in the field have presented conflicting research as to which organizational form is best suited for the delivery of a particular service yet, the literature has provided a broader understanding of the use of certain organizational arrangements for the delivery of services to the public. Policy planners are likely to find that in some cases policy objectives are much 
better served by the market and in other cases the policy objective may be better served by government agency. Because factors such as labor market institutions are outside the purview of local governments, it is not surprising that public and private production of publicly funded services continues side by side in spite of cost differences. In refuse collection, there is evidence that efficiency alone is not a basis for determining which refuse collection service arrangement option will be chosen. Using private organizational arrangements with the belief that private arrangments can produce lower cost may prove disappointing for municipal governments. Basing choice on cost alone may not produce the desired results hoped for by municipal governments. Research into the nonmonetary outcomes associated with the use of different types of institutional service arrangements can promote further discussion and understanding in both bureaucratic processes in decision-making and in municipal service delivery systems.

Summary

The literature on municipal services delivery and organizational arrangement often cites refuse collection as part of an analysis of municipal service delivery. The exploration of policy questions for municipal services has produced literature which analyzes models and theories of public policy in relation to private and public institutional arrangements. The debate has been centered around which service arrangement will produce the best results for citizens. 
Answers are not precise as to which organizational form is best suited for the delivery of refuse collection services. There are limits to the use of private organizations in the delivery of public services, and public tasks such as refuse collection are best delivered when the task can be measured and public oversight has been established for quality control. The evidence for relative efficiency of public versus private organizations performing similar tasks is, however, not clear, and the differences are often subtle. It is clean that the use of a single criterion for choice of private organizational forms (e.g., the belief that low cost alone will produce the best service option) may not create the results desired by municipal governments.

The literature does not offer a clear delineation of choices between government provision and private provision of services. While there is the commonly held belief that cost is the overriding factor that determines the choices made in the area of service alternatives, the literature does not conclusively point in that direction. Other factors that influenced choice include legal considerations, traditions, the number of potential suppliers of the desired service, strong opposition from other sources, and large start-up costs associated with a municipal refuse collection and disposal system.

After consideration is given regarding how the same variables give different outcomes within the framework of different government jurisdictions, refuse collection through a regulated private arrangement appears to be as efficient as other arrangements studied in the literature. 
There is evidence that competition rather than organizational arrangement is the crucial factor when it comes to efficiency in refuse collection services. 


\section{Chapter 4}

\section{RESEARCH METHODOLOGY}

\section{Introduction}

A research project that is qualitative can examine policies through the collection of data from records, interviews, and field observations. Qualitative research continues to be a valuable research strategy and, as Pfaffenberger (1988) has suggested, is enjoying a renaissance as a tool for scientific discovery. The qualitative approach has also been validated by McCracken (1988), Agar (1986), and Rein (1981). The qualitative process includes observing, documenting, analyzing, and interpreting the meaning and values of general characteristics of phenomena within the traditions of people (Agar, 1986). Focusing on traditions and history in order to capture data in its original setting, the qualitative approach can also allow for the collection of unforseen data. As Agar (1986) has suggested, the ethnography seeks to interpret, in neither a completely subjective nor objective way, the traditions of the audience being studied.

Rein (1981) has suggested that one approach to the direct empirical study of use is the case study method, in which a single policy area is identified and, within that single policy area, a single substantive policy issue is identified for study. Guba (1985) has also made this claim and has stated that policies cannot be tested directly, only programs can be tested. To understand the decision-making process by government bureaucrats in a policy area, an investigation would have to be done with a specific service, 
within municipal services, that are delivered by municipal government in order to study how decisions are being made by bureaucrats. This study examines refuse collection services in relation to the choices available in policy options for alternative service delivery by municipal government. This is a study that takes refuse collection as the single substantive policy area and uses qualitative methods to analyze data frorn the experiences of people in the field of refuse collection. These experiences provide the raw data for an analysis of those factors that influenced the decision-making processes in the choice of service arrangement alternatives. Using Agar's (1986) approach as a model, interviews were conducted to learn how public officials and private haulers view refuse collection operations. The interviews capture from the people interviewed their own understanding of their history and the current dynamics of the refuse collection systems in operation in the cities of Portland, Gresham, and Beaverton, Oregon.

\section{Research Design}

The goal of this qualitative research design was to obtain information from private garbage haulers and public officials $\mid$ about the refuse collection industry in Portland, Gresham, and Beaverton. These three cities were chosen for the study to examine those types of service arrangements being used in each city. The tasks of this study have been to conduct face to face interviews, obtain field records, make field observations, and review Public Choice literature to gain an understanding of refuse collection in three local 
cities and to gain an understanding of the dynamics which influence or cause government to make decisions about service delivery. The Ethnograph (1988), a computer software program for processing text into data sets, was used for data reduction and analysis.

Information about the refuse collection industry operating in Portland, Gresham, and Beaverton was obtained through direct interviews with public officials and private owners of garbage hauling businesses and from secondary sources, such as city ordinances and publications that provide service descriptions of programs.

A discussion about waste disposal (see Chapter 1) is presented with an exploration of the decisions which have stimulated proposals for change in policies for solid waste haulers. A review of alternative service arrangements in other U.S. cities ( see Chapter 2) has also been included to provide background information on municipal collection, as well as other service delivery arrangements not found in the three cities in this study. A review of the literature (Chapter 3 ) on municipal collection and alternative service arrangements has been included to augment the information obtained from interviews, field observations, and public and private records.

To explore decision that were made regarding choices for alternative arrangements for a refuse collection system, the attributes of public officials are examined. Attention is given to both those pressures for change that come from within the jurisdiction and those pressures that come from 
outside the jurisdiction. An examination of the process which municipal government and the garbage hauling industry have used to respond to change was reviewed to ascertain how they seek to make changes.

Selected management technologies from the national study conducted by Stevens (1984) have been incorporated into the study of the three cities (see Chapter 5) to examine management technologies of garbage collection companies in the three cities to ascertain whether companies in the three cities have any of the same characteristic as those of the 20 cities in the study completed by Stevens.

\section{Data Collection}

Data came from two primary sources. The first data source includes face to face interviews and field notes. The second data source includes a review of the literature and of public and private documents.

Criteria for participation in the study were developed for both public officials and private haulers. Public officials had to be either past or current employees, past or current elected officials, or formerly or currently appointed individuals who had worked or were working for the jurisdiction. They had to have served or be currently serving in an official capacity for the jurisdiction and had to have worked or currently be working on refuse collection issues. Private haulers had to be providing services to one of the selected cities or had to have provided services in the past.

All haulers were contacted by telephone and asked to participate. Calls 
were made to confirm appointments. Garbage haulers who did not participate in the study indicated they were either too busy, did not return telephone calls, or simply said no and gave no reason. In Portland, one hauler refused and gave no reason, two haulers did not return calls to schedule an appointment, and one hauler indicated that there was a time constraint and he could not participate. In Beaverton, one hauler did not return calls to schedule an appointment and left a message with the secretary indicating that a busy schedule prevented participation in the study. Another hauler simply refused and gave no reason.

Data were gathered from public officials who were either currently working as an employee or serving in a professional capacity for one of the jurisdictions and from the private haulers who were either operating a business in the jurisdiction or had operated a business there. Face to face, audiotaped interviews were conducted at the office of 19 individuals who participated in the interview process. Office interviews permitted the researcher to observe the business site. Two interviews were conducted at the office of the researcher, and one interview was conducted at a public facility. Interviews were conducted from May 1992 to October 1992. Data were collected from a total of 22 individuals from the three cities under study. Additional data were gathered from documents from private businesses and public organizations. Table 2 is a summary of the participants by jurisdiction. 
Table 2

\section{Participants}

JURISDICTION

\begin{tabular}{lll} 
PUBLIC & PRIVATE & PRIVATE \\
OFFICIAL & BUSINESS & ORGANIZATION \\
\hline
\end{tabular}

CITY OF GRESHAM

$$
N=3
$$

$$
N=3
$$$$
\mathrm{N}=0
$$

CITY OF PORTLAND

$$
\mathrm{N}=3
$$

$$
N=6
$$$$
N=0
$$

CITY OF BEAVERTON

$\mathrm{N}=3$

$$
N=3
$$$$
N=0
$$

STATEWIDE

$\begin{array}{lll}N=0 & N=0 & N=1 \\ N=9 & N=12 & N=1\end{array}$

There were a total of nine public officials from each of the three cities. There were six private garbage haulers from the City of Portland, three private garbage haulers from the City of Beaverton, and three private garbage haulers from the City of Gresham. The private garbage haulers were owners or corporate officers of the waste hauling businesses. One private official represented a statewide association of small independent waste haulers which locates its statewide office in Salem, Oregon.

While the interviews were structured through the use of a questionnaire, the structure of the questionnaire itself was only to provide for consistency rather than to guide the informant in any particular direction. This semi-structured interview technique allowed the informants to share their experiences as they had lived them, freely giving their impressions of the dynamics of their city from an historical perspective. The informants 
were also encouraged to give their current analysis of the city in which they work and/or live. In addition, the informants provided factual information in such areas as city ordinances, yard debris and recycling programs, and the fiscal and technical operations of their businesses.

Current public employees managing refuse collection services were contacted and asked to participate in the survey. The employees were asked for names of individuals who had worked in the past in a public capacity. Those individuals, in turn, were contacted and asked to participate in the study if they had participated in the development of policies for residential refuse collection. A list of registered business owners doing business in each of the three cities was obtained from public officials at the public agency of each jurisdiction.

There are a total of 68 haulers operating residential refuse collection businesses in Portland, 10 haulers operating in Gresham, and 7 haulers operating in Beaverton. Data were obtained on: the scale of operation, level of service, and management practices of these local service providers. The scale of operation included the amount of refuse collected and the number of pickups in an eight-hour shift. The level of service measured the frequency of collection and the type of household refuse collected.

\section{Coding and Analysis}

The process of analysis began with assigning codes to the audiotaped conversations. Analysis of the data was completed in three phases. 
Phase one was the transcription of the tapes by a professional typist. Each taped interview became a separate transcript for coding and analysis. The typist used a computer word-processing program that placed the narrative on the left two-thirds of the page. The right one-third of the page was left for coding and note taking. The transcriptions were each assigned an identifying code so that the confidentiality of each informant was preserved. The transcribed text was converted to computer language for use with the ethnographic computer software package.

Phase two began with numbering the transcripts to begin the coding process. The numbering of the transcripts allowed for coding for analysis within each of the larger data sets. After the transcripts were numbered, they were then hand sorted based on observations of themes within the text. After the manual sorting was completed, the numbered transcripts were converted for coding. The themes were then entered into the computer program with the numbered text, and the coded information grouped by themes became code sets. The computer program generated numbered code sets with start numbers and stop numbers. The computer program created files for the code sets so that themes identified could be grouped. The computer-sorted codes were grouped into files and became the output file for each theme. A computer generated printout was made for each transcript based on themes.

Since there are two major sources of information that make up data seis (public officials and private solid waste haulers) the data were segmented 
within each of these two categories. All the transcripts from the interviews of public officials were grouped into catalogs where themes of data could be grouped. All the transcripts of the private solid waste haulers were grouped into catalogs where themes of data could be grouped. Each code set was then grouped by themes with the catalogs which produced outputs of data. The process of constantly comparing transcript segments to each other (a manual process completed along with the computer ethnographic process) was also completed in order to assure that the computer program was functioning as it should.

The final phase of the data analysis process was assessing the quality of the data sets and turning data sets into text based on the experiences of the people interviewed.

\section{Limitations}

Data collected from local haulers were not verified through their records. Most companies did not provide budget information or actual company records because of suspicions about the intent of the research. Financial data and other company information, such as cost of equipment or cost of labor, were given in estimates or ranges. For example, one company owner asked whether the research was being completed for another competing company operating in the area. About halfway through the interview the owner again asked whether the research was being completed for a competitor. Most individuals indicated that their company records were 
their personal finances (and financial records could be personal, as these were small family owned and operated businesses) and that they did not want to provide this information to their competitors. Data on the scale of operation and management technologies were also given as an estimate or in ranges. For example, when one hauler was asked the percentage of the 8-hour shift used for driving to and from the disposal site, the response was 10 to 15 percent.

There was an inability to obtain information from the records of public hearings and public publications from past years. One individual in Beaverton indicated that some records simply left with outgoing administrations, and he knew of at least three changes in administrations. Public officials in Portland indicated that the minutes from public hearings were either lost, destroyed, or perhaps stored in the archives. Should the records actually be stored in the archives, it would take years to actually find the records of interest.

A strength of this study of three cities is that those individuals representing the public contributed, collectively, more than 10 years of public experience in the refuse collection industry. On the private side, the history came from individuals with family histories in refuse collection that began around the turn of the century. Only one individual had five years or less experience in Oregon; however, that individual had more than 10 years experience in another state working in the refuse collection industry. Some 
of the solid waste haulers were currently serving (and had been serving for a period of time) in a policy role with local government planning within the jurisdiction. 
Chapter 5

\section{FINDINGS}

\section{in}

Introduction

The history of refuse collection and disposal in Portland, Gresham, and Beaverton has importance to anyone with an interest in municipal service delivery systems in general, and specifically, to anyone with an interest in refuse collection as a municipal service. The information in this chapter details the development of refuse collection in the three cities from the turn of the century, when refuse collection began as a function of disposing of unwanted materials, to its current operation as a service arrangement of municipal governments. Many elements of the refuse collection system in each of the cities under study continue to function as they have since the turn of the century, and many of the same businesses that were picking up garbage at the turn of the century are still doing so today. This reporting, as told by the garbage haulers and other people involved, gives some indication as to how they have influenced the development of municipal policy and how municipal policy has been influenced by external forces.

Rapid changes have occurred in the cities under study. There was a time in Portland when garbage haulers needed only to obtain a business license to pick up garbage and take it to the landfill. However, while the essential tasks of refuse collection and disposal remains the same, legal mandates that guide the actual pickup and delivery of garbage to the landfill 
have changed the essential tasks of refuse collection to a process that has become more and more complex. Stated simply, garbage collection and disposal is no longer a process of picking up garbage and dumping it. The adage "out of sight, out of mind" has changed. The process of waste stream reduction has developed as a result of mandates from federal and state legislation, and garbage collection and disposal, guided by legal mandate, has become a mechanism by which to reduce the solid waste stream. This mandate has defined garbage and quantified the methods of both collection (manual or mechanical) and disposal.

In their interviews, informants suggested that the regulatory changes for refuse collection in each City were recommended by those who had extensive knowledge and understanding of the historyl of the refuse collection system in the three cities. Informants spoke freely from personal experiences about the issues of the three cities where they worked. None of the haulers were new to the business of refuse collection. All public officials interviewed had been involved in waste management more than five years and had served in various capacities within City government either as a council member, a staff to City Council members or bureau administrator, or as a citizen who had membership on planning committees studying the issues of waste management. Examples of their expertise include an individual who had participated in the negotiation of the franchise system between garbage haulers and the Portland City Council and another individual who served on 
the first Solid Waste Advisory Committee. Additional examples of expertise include a college graduate who started in the business at age 12 by helping his parents and now operates a refuse collection business of his own, as well as an owner who has had several routes that extended across several public jurisdictions. One public official indicated that he had conducted three franchise studies, and another indicated that he worked in at least two jurisdictions. These people understand the history, the problems, and current issues of the waste management field in general and have had specific firsthand experience with the refuse collection system.

Informants were asked questions about the history, tradition, services, politics of the city, and the day to day operation of refuse collection. Themes that developed from analysis of the interviews have been organized into the categories of Background, Tradition, Service Arrangements, Bureaucracy, Change in the System, Political Dynamics, Uniform Implementation, Recycling, and Management Technologies.

Background

At the turn of the century, garbage hauling was mostly a father-son family enterprise. Many of the people in the garbage hauling industry in the three cities are third and fourth generation owners of their businesses. It was not uncommon for great-grandfathers or great-uncles to have started these garbage collection businesses. One business owner stated that his uncles and his father started their business about 88 years ago in the Portland 
metropolitan area. Another individual stated that his great-grandfather began his business in 1904 with a horse and buggy outfitted with wash tubs and that he walked his route. This individual indicated that he purchased the business from his father and that his father had purchased the business from his father who had purchased it from his own father (Interview, 010).

The unglamorous but necessary business of garbage collection often started with the hauling of one's own garbage along with one's neighbor's until there were enough customers to consider them a basis for a route. After a route was established, the hauler protected it. It was the Germans and Italians who started hauling garbage in this manner. The business was loose and evolved by word of mouth.

Originally, hauling garbage was not a complex process nor a complicated business. A hauler did not need to have a business license. The level and type of services offered to the resident was negotiated between the hauler and the residential customer. Billing was also negotiated between the hauler and the residential customer. If there were any problems, the customer simply found someone else to pick up the garbage and haul it away. If the customer did not pay for the service, the garbage hauler simply did not pick up the garbage. In the early days nobody cared how much a truck weighed, how well the brakes worked, or how the employees were managed. No agency wanted to know if employees were using drugs or had a driver's license. It used to be that if a person owned a truck, any type of truck, and if 
he could get enough customers to pay whatever he charged, then he could pick up the garbage and haul it away somewhere and dump it. That was it. Businesses were small. Customers were developed by the owner of the business through personal relationships and contacts in the community, and customers were maintained through the personal relationship. The garbage hauler knew his customers well and the entire business transaction was conducted on a personal level. For example, if someone forgot to put out the garbage the hauler checked with the customer to get the garbage hauled away. Billing was done on a personal level. If there were a problem with the billing, the hauler worked it out with the customer. Consequently, when a business was sold there was a personal transfer of the business. I The transfer first went to a family member. When the business could not be transferred to a family member it was transferred to someone known to the family. As one hauler put it,

With that business, generally speaking, you got the truck and the customer list and you rode around with the guy and the guy introduced [you] to his customers and it was a real personal type of thing. And then [you] would take over the business. (Interview, 010) The business was sold to an outsider only when a family member or a family friend was not available to take it over. Thus, new owners were readily accepted most of the time. The new hauler made it part of the business to continue to operate the business on the personal level.' 
Early in the development of garbage collection routes, the haulers were mostly concerned with attending the day-to-day operation of their business, that is going out and doing the work. An individual did this by building on the customer base and by carrying on the tradition of two, three, or four hours of work hauling garbage each day as their fathers and grandfathers had done in years past. The garbage haulers were concerned with providing services to the route and maintaining the routes. This was done by providing good personal service and enforcing non-formal rules governing routes that were set by tradition. The haulers, as a group, set out to get customers, pick up the garbage, dump the garbage at the landfill, and go home at the end of the day. At the end of the route, the haulers met at the local tavern, where many of the traditions that had been established were continued and many business decisions were made. The haulers as a group had not formally organized politically to achieve common goals.

In Portland's private open competitive system where there were few formal rules, there were no formal rules that said there could be no competition on a route. There were hundreds of people with trucks driving all over the city picking up garbage. The better established haulers with more customers remained in business while the least established haulers went out of business. If a refuse hauler had the majority of the houses on a particular route, it was understood that this was that hauler's route. In Portland, tradition helped establish route territories. Once a route was established that 
route belonged to the hauler who established it, and the refuse haulers respected each others routes. However, if a new hauler did come into an established route, this caused some animosity: Tires got slashed, trucks got burned. Portland's present residential refuse collection system was adopted in the early 1990s, and at that point residential routes were assigned to haulers as part of the overall ordinance regulating garbage collection. This ordinance establishing the franchise system for residential refuse collection ended the open competitive system for residential refuse collection.

In Gresham and Beaverton the open competitive system ended more than two decades earlier. Residential refuse collection routes in those cities were already established. In Gresham and Beaverton there has been little turnover of garbage collection businesses, and many of the same businesses that were picking up garbage at the turn of the century are still doing so today. Only one company went out of business in Gresham, and in Beaverton there was one merger. In the early 1980s one garbage hauling company sold that business and sold the company that was licensed by the City. In Beaverton, no garbage collection business in operation has been denied a renewal of a business license or franchise. In most cases, the same garbage haulers have continued to operate businesses providing garbage collection services. Therefore, the people who operate the refuse collection businesses in these two cities are very stable. When licensing was adopted in the early 1980s by Gresham and Beaverton, those refuse haulers already 
serving customers were grandfathered in, and routes were established by City ordinance.

Since the 1940s, even without regulation, many of the garbage hauling routes in the three cities have had little change. While public officials in Portland did not regulate the routes, haulers were given implicit support which functioned like a regulated system for the garbage haulers since the early 1970s. One informant commented that,

The City of Portland's method of garbage collection has had implicit City support for years. In the 1970 s the garbage haulers allocated routes. They allocated routes to the level that twice the U.S. Attorney General investigated them for anti-trust and collusion. (Interview, 020) After Portland began regulating garbage collection in 1992, , there were some changes in route boundaries because of overlapping that existed among established garbage haulers. The garbage haulers operating in Gresham and Beaverton were incorporated into those cities as franchised garbage haulers when the boundaries changed. The haulers knew that when annexation became effective it was automatic that a hauler would be required to become franchised by that jurisdiction and they would have to apply for a franchise. When franchising was adopted in Gresham and Beaverton, the existing boundaries of the garbage haulers were identified and the haulers were told, "Yes, you are the guys [and] these are the franchise boundaries" (Interview, 021). In other words, the original, established boundaries were kept in mind 
as the routes were formalized by ordinance in Gresham and Beaverton. While many of the established routes were effected by changes in route assignments in Portland, efforts were made by public officials to retain the informal route system and to retain the original garbage haulers who had developed these routes prior to franchising.

While early regulations by Gresham and Beaverton were concerned with routes of the garbage haulers, a shift in the emphasis of regulations from routes to service delivery came as environmental concerns became greater. One official sums up the shift from regulating routes to regulating services with the following comment:

I think politically once that realization [came] that the area didn't have an infinite amount of space to get rid of [the] solid waste, [the politicians and bureaucrats] had to address it. And once they started addressing that issue, it forced them to address other solid waste issues concerning collection and recycling. (Interview, 015)

It had become common knowledge that some products are not compatible with the environment and, because of this incompatibility, precautions must be taken in order to ensure that no human, animal, or plant was being harmed. In the mid 1980s the state legislature passed a law (Senate Bill 66, passed by the 1991 Oregon Legislature) which mandated every municipality in the state with a population over 4,000 residents to implement some form of recycling program as part of an effort to reduce the waste stream. Local 
jurisdictions were required to provide curbside recycling service or recovery services to residents. Cities with a population of less than 4,000 were exempted from this requirement. Portland, Gresham, and Beaverton had garbage service collection with various levels of recycling and other services being offered to residents. These cities needed ordinances to implement better programs to reduce the waste stream and to come into compliance with state law. Each of the three local governments had to submit to the regional government plans that would identify revenue sources to fund a waste reduction program and identify how recycling would be implemented.

Franchising was the method Portland used to meet new requirements to reduce the waste stream with recycling services without implementing a municipal refuse collection service. Gresham and Beaverton made adjustments in their ordinances to meet new state requirements. It soon became apparent to the garbage hauler that a different level of business operation was being required by new laws and the franchise or license agreement that developed out of these laws.

\section{Tradition}

Traditionally, garbage collection has been provided by private businesses in Oregon. One public official, commenting on why private businesses continued to be used, said that

One reasons is [that government] has companies that have been operating at a very high satisfaction rate and a good level of efficiency. 
For a municipality to take that over would involve a large up-front capital investment in equipment. ... To change ... from the private to municipal service there would have to be some problem, some crisis that would push [government] in that direction and that has not happened. ... (Interview, 014)

In Gresham and Beaverton, there has been almost no turnover, and no one has been denied a renewal. Only one garbage company has gone out of business. Of the companies that are providing service in east county, all have been in operation for years, and many of the same garbage companies that were in operation before regulation continue to be used. Of the garbage hauling companies originally in operation in Gresham and Beaverton, almost all are still in operation. Businesses have been passed on to the next generation, with the children becoming involved in the garbage business as teenagers. Individuals can trace much of their family history through their family business. In Portland, some of the garbage haulers are driving to the same houses their grandfathers drove to. One garbage hauling company owner stated that his father had operated a business in Portland and that the company subsequently moved to the west side and began operating in Beaverton.

While many of the older garbage haulers have turned their businesses over to their adult children, some of these adult children have not wanted to continue with the business. When the adult children did not want to 
continue with the garbage business, keeping the business in the family or with friends was a challenge. One public official portrays this process of the tradition of transferring garbage hauling businesses:

The sales in the business has traditionally been to other haulers. A lot of these guys are now in their late 60 s and these men have turned over their businesses to their kids. Some of the kids have gotten into the business and some of the kids didn't. And [the haulers] did not want to sell their business to people outside of the business. They only wanted to sell to two types of people in general and those are family or somebody in the industry. They do not generally seek anybody outside the industry. A lot of the deals are never known. It's always somebody who went to them and said, "Look if you don't sell to your son, give me a call first, OK?" And that is the deal that has been spoken for 10 years. (Interview, 020)

The older business owners do not want to sell their companies to the highest bidder. They wanted to keep the tradition of keeping the business in the family. This fact was emphasized when the above informant continued with this description of the transfer of ownership of the garbage businesses:

There is nothing illegal, they just sell to people they're comfortable with. There used to be a tavern just outside the gate to St. John's Landfill called the Blowfly. The old Blowfly -- really funky but the new Blowfly is nice and funky. And these guys would be in there after two 
o'clock and having a beer just as working guys do. But . . some of these guys were executives with ten trucks and they grew up driving pappy's truck -- then the town grew and ... now they have a nice office that dispatches and they're doing everything else, but their afternoons are still just spent doing the same old thing, stopping by the Blowfly once or twice a week and playing cards. So what you end up with is that they don't have anyone else they want to sell to. They want to sell to their own guy. (Interview, 020)

Many of the haulers gave examples of being able to trace much of their family history in the garbage collection business through pictures and other personal records.

Clearly, many companies operating in the three cities are old and ownership of these companies has been transferred to family members and to close family friends. Given the tight-knit family nature of the garbage hauling business, it's not surprising that when a very large company began a business operation in the residential refuse collection market in Portland the reaction was intense suspicion and fear, especially regarding the manner in which the business began its operation. It was the manner in which this company operated that forced many longtime haulers who in the past had resisted any type of government involvement in the residential refuse collection, to accept the view that government intervention through franchising was a way to get protection, keep most haulers in business, and 
prevent an outside company from forcing old companies out of the market. So while franchising became a method to establish service levels, it also served to protect service routes and keep out unwanted competition.

To summarize, tradition has played a large role throughout the evolution of the refuse collection in the three cities. Even after the switch to franchising, local public officials continued with the same haulers, who continued to serve the same districts with the same customers. Both the public officials and the private haulers have suggested that this refuse collection as a system "just evolved." In addition to the natural evolution of routes and service in the garbage hauling business, it is also clear that franchising may actulally have had the effect of stabilizing current arrangements and traditions. One interesting facet about the local garbage hauling industry is that the older garbage haulers who continue to operate businesses are locked into traditional ways of operating their businesses and are resistant to change. It has been a challenge to re-educate haulers, to show them the value in retooling to develop recycling as part of their business, and to convince thern that they are not just hauling garbage. Things have become more complicated as the system has grown, and legal jurisdictions are placing demands on what, in the past, was a simple task to perform.

\section{Service Arrangements}

Service arrangements developed both through tradition and in response to social changes. Studies were initiated in the 1970 s and 1980 s by 
the City of Portland and in the 1980s by the City of Gresham to assess local government options and to assist officials in making the best decision for refuse collection service arrangements for those cities. No decisions were made as a result of these studies done in the City of Portland, and so Portland continued with an open system where private garbage haulers provided the refuse collection services. When Gresham commissioned a study to examine alternative service arrangement options for refuse collection service in that City, its planning committee chose to continue with a regulated system and continue with the private garbage haulers who had been serving the City. One public official made the following statement:

We looked at [options for service arrangement] and one of our first reports addresses the very issue: What's the best selection we can have here? . . three options: municipal collection, a franchise, or a contract. We pretty much ruled out municipal collection in trying to say, let's keep it on the private side. (Interview, 004)

One informant indicated that prior studies on service delivery options conducted in the 1970 s by the Portland City Club revealed no political support for change in the service arrangement option. There was also little support from Portland garbage haulers and the general public, and most of the resistance for any type of change in the service delivery system came from the garbage haulers. One private hauler in Portland explained the reaction to the studies on service delivery options in this way: 
I think it was a couple of different factors, one being public policy [in Portland] . . . to support small local business. And we are small local people, we work here in Portland, we spend our money in Portland. I think it's proven throughout the nation that private enterprise can provide a more cost effective service than a municipality. (Interview, 012)

More than one informant indicated that the bigger philosophical question of public residential refuse collection versus private residential refuse collection was answered long ago when Gresham, Beaverton, and later Portland simply incorporated private haulers into newly developed franchised systems. One public official made the following comment: I guess it never occurred to me. It was in the charter of the City [where] I was the manager and it never occurred to me to ask how that decision had been made. It had just been made, and I knew that when the franchise came up, if I wasn't happy with the franchised hauler, I could put [the franchise] out for bid for a franchise. So, I honestly can't tell you who and why and for what the decisions were made to franchise or license.... (Interview, 015)

For Portland, Gresham, and Beaverton, there has been no ongoing debate around the merits of public refuse collection versus private refuse collection. There has been no ongoing debate because of general beliefs held by both private haulers and public officials that private collection is better. In 
Portland, service option debate did not include municipal garbage collection, and as the boundaries of Gresham or Beaverton expanded, garbage haulers were incorporated into the franchise or license system without debate. One informant made the following comment:

Since I have been here, of the ten companies that have been providing service, all ten of them have been in operation in the east county area for literally years. As we annexed [new land into the City], we were also annexing and picking up new areas [with haulers] that had to be licensed. (Interview, 014)

There was the assumption that the garbage haulers already serving the annexed land would become part of the regulated system. Gresham ordinance cited an intent to protect the current garbage haulers in operation in the City. The City of Gresham adopted a license refuse collection system in subsequent ordinances that allowed for the continuation of the firms that were already established in the jurisdiction. Gresham also continued to be divided into solid waste collection districts, and it granted a license to one garbage hauler for all customers located within each district. Solid waste collection licenses were issued to all garbage haulers with no changes to the route boundaries. In 1988, Gresham did a study of the refuse collection services alternatives in response to concerns about the management of the solid waste stream. Gresham examined the refuse collection system it had operating at that time and then explored the major advantages and 
disadvantages of alternate refuse collection systems to determine what type of solid waste collection system would work best in that City. The alternative solid waste collection systems explored were municipal collection, franchise or license, contract, and private open competitive.

Local jurisdictions never seriously considered adopting a municipal refuse collection system in part because no one was ever willing to make the political move of advocating a municipal refuse collection system. A private garbage hauler emphasized local philosophy in this way:

You can go and look at historical data throughout the U.S. on what municipalities are doing, and you find that there are municipalities getting out of that service as fast as they can.... They can't do it as cheap. (Interview, 016)

It was simply incomprehensible in this three city area that a local government would tell all private business people: Sorry, the City is going to take this over. A public official gave this perspective to the local philosophy: The cities control the franchises currently. The cities could still at the end of the franchise period decide that they want to get into the business of hauling solid waste and that would be a council decision and as far as I know, very seldom do they even think about doing it because it would be a huge startup cost for equipment and the other matters. (Interview, 015) In summary, while there the three cities can at any time make the 
choice to adopt municipal collection, the bureaucrats have retained the private sector as the resource for delivering refuse collection services. There was the perception that the private sector, given a gecgraphical franchise and with proper monitoring, could actually provide the service better than municipal government. Should the cities develop municipal services, they would have to start a service that would function as a utility, create huge startup costs, be labor intensive with ongoing costs that would effect City budgets, and put private haulers, who have provided the service for years, out of business. While politicians and bureaucrats could have chosen to provide municipal refuse collection, the cities did not make that choice.

\section{Bureaucracy}

As changes were being mandated from federal and state governments to reduce the waste stream to meet new environmental goals, the City bureaucrats' challenge was to get the refuse haulers to move away from their previous concepts about garbage collection and to move toward the new concept of recycling as a part of business. As this process was being implemented, the garbage haulers indicated that there was too much bureaucracy and a loss of control. Too much bureaucracy was a common theme among haulers, and too many garbage haulers was a common theme among bureaucratic officials. Haulers indicated that bureaucrats |control the level and quality of services, the condition of the trucks, the types of trucks necessary for the operation of the business, the rates charged to the residential 
customers, how and when to bill the residential customer, and how and when services can be terminated and for what reasons. The bureaucratic officials control the process for collecting unpaid bills and pricing, through rate setting. While the garbage haulers were delivering the same type of services as they had in prior years, the changes required by bureaucrats were felt by garbage haulers when they no longer had the ability to stop delivering services to a non-paying customer without first going through bureaucratic channels, and when making changes in other aspects of the service delivery operation without notifying local public officials. A private hauler made the following comment:

What has changed is your ability to make business decisions. A lot of that ... either has been quantified or usurped ... because at one point, we had a description of the vehicle that we were going to buy, not just what makes sense for your service area or what makes economic sense for your business, but this vehicle--this configuration. It didn't say make and model, but it said this configuration. Well, maybe it works for you and maybe it doesn't, and individual business decisions need to be based on what works and what gets the job done. (Interview, 021) The monitoring required by the bureaucrats is almost overwhelming to the garbage hauler, who is required to report information in such areas as materials collected and income. Since Portland implemented the franchise system in 1992, everything is mandated, even the condition of the trucks and 
the working hours. This certainly indicates a of loss of private control. To paraphrase one garbage hauler; whenever government gets involved, it has first to protect itself, then the customer, and then the garbage hauler. The bureaucrat knows the individual's business as well as the owner's.

One garbage hauler serving the City of Portland indicated that it has been difficult to refrain from complaining or from feeling as though all control for the private operation of a business has been lost. However, the difficulties inherent in having private haulers controlled by government bureaucrats, informants not withstanding, (both public and private) reported that the whole point of this arrangement was that public officials did not want to put refuse haulers out of business. One informant, speaking generally on how garbage haulers are used, made the following comment:

For the most part, rather than getting into the business of doing solid waste and hiring mare City employees and doing those kinds of things, it was generally thought that private industry, given a geographical franchise where they can provide a service that was monitored by the City, was better than the City going into business itself. Better from a service point of view and a cost point of view. (Interview, 015) In fact, a general belief among garbage haulers and bureaucratic officials alike is that planning for refuse collection in its present form was a process not necessarily based on cost or efficiency; it was based on a desire to keep current service arrangements (more specifically, the desire to not put local 
garbage haulers out of business) and on the need to meet new demands for change in the refuse collection system. The desire to continue with the established service arrangements was confirmed by both the public officials and private haulers. The franchise system was chosen as a way of regulating rates and maintaining a stable system. Bureaucrats in Gresham wrote language into jurisdictional codes to protect current, small family-owned businesses as changes were being made to respond to new legal mandates. The desire to continue with and protect the garbage haulers was confirmed in public records. A public official from Portland made this statement:

We pretty much ruled out municipal collection ... lets keep it on the private side as much as possible ... municipal crews could clearly take away something that the private companies were doing and there didn't seem to be any argument that would increase efficiency or really gain anything for the citizens. ... If you've got private, what is the best way to go? ... If we contracted there would be a limited number of contract recipients--four--and given that when we initially authorized the franchise agreement ... there were 69 haulers, you'd be putting a heck of a lot of them out of business. We felt a better approach would be to utilize the experience and the strength of the existing program that was out there, to use all these guys that have been in business so long, and to set up a framework where they could operate more efficiently. (Interview, 004) 
However, since changing from a private open competitive system to a regulated franchised system, at least one bureaucratic official in Portland has expressed a desire for only a few big haulers so services can become more efficient. This public official privately expressed a desire to have up to three major haulers in Portland so there could be more control of the service. A sentiment expressed by at least one garbage haulers was that bureaucrats have a preference for dealing with the office personnel of a large company rather than a small, independent garbage hauler. The public officials of the City of Portland have encouraged mergers to "squeeze the little guy out" in order to reduce the number of haulers serving Portland. One hauler commented that bureaucratic officials don't want to deal with that many small independent haulers:

They're trying to encourage us to merge with each other. Now we don't have to do that because we are a middle size [company], but the little companies have to sell out or merge with somebody else. (Interview, 003) More than one garbage hauler expressed concern that pressure was being placed on the small and medium-sized garbage haulers to merge. Since the City of Portland changed to a franchise system, some garbage haulers have gone out of business or merged with other companies. Many small companies (one-truck operations) could not meet new financial requirements necessary to continue to provide services. The really small garbage hauler 
could not meet new requirements that were developed in planning committees that were responding to state mandates.

Bureaucrats in Portland and Gresham created planning committees, which consisted of people from the community, the garbage haulers, and public officials, to help with planning for refuse collection. The City of Beaverton has done internal planning and used the public hearing process to obtain feedback for planning. Bureaucrats in Gresham made recommendations to City Council based on planning committee recommendations. In Portland, most of the planning was done by consensus, and due to legal mandates some of the planning was seen as preplanned and presented as an $\mu$ ltimatum. Smaller garbage hauling companies in Portland and indicated that large companies had more influence with public officials in the planning prodess, a sentiment concurred with by some public officials. Garbage haulers were required to accept recycling as part of the franchise agreement. However, bureaucrats worked with the garbage haulers to help them meet the requirements for new equipment for the delivery of the new mandated services adopted to achieve waste reduction goals. For example, the length of the license or franchise allowed the refuse collection haulers to use that franchise agreement between the City and the garbage hauler to finance new' equipment with lending institutions. In Portland, the negotiation process to work out rate structures and route 
assignment, along with the change in the franchise system, went something like this, according to a public official:

The haulers said to us, "We have to buy pretty expensive equipment these days, that have more than a five-year life. When we borrow money, we often borrow it for more than five years. The banks want to see that we have a license that is as long or longer than the term of the loan. So, why can't you give us a ten year license?" And we said, "Gee, ten years is a long time. How about if we give you a ten year license with an evaluation period at five years. So you can take your ten year license to the bank if you need to borrow money, but in five years we'll take a look at your service, and if you're not up to snuff we'll pull your license." And they said, "We're not crazy about that, but if that's the best we can do, we'll do it." So that's the system we use. (Interview, 007)

Planning has been done by bureaucrats for rate setting for the financial management of the refuse collection system in each of the three cities. The municipal government conducts rate studies to determine costs for the pickup and dumping of residential refuse and to ensure that the haulers make a profit and ensure stability in service delivery. Government regulates the rates and, as part of that rate making process, establishes levels of service and makes sure that customers are satisfied. Rates are set so the average refuse collection hauler can make an average rate of return. For the purpose 
of rate setting in Portland, the refuse collection haulers are grouped into average small-sized hauling companies, average medium-sized hauling companies, and average large-sized hauling companies (Interview, 019). The process of rate setting may not work too well for the below average size hauler and may force some refuse haulers out of business. One hauler made these comments about the manner in which rates were set and routes were established and assigned:

The smaller companies like ourselves have to play on the same level field now. We pay the same, charge the same rate, we have to-obviously--provide the same level of service and the same level of standard all through our collection efforts. (Interview, 005) In years prior to rate setting, the garbage hauler could charge rates that would allow for differences in route conditions. For example, some routes have more apartments with lower income customers who do not always pay their bills in a timely fashion. The rate process had not taken customer responsibility into consideration when rates were set. As franchising was being established in Portland, routes were assigned based on revenues and not on tonnage of waste being collected at the residential home.

There was agreement from both private haulers and public official, that by franchising, government has guaranteed the haulers a profit. Both private and public officials also agreed there were limitations to profit and loss for the garbage hauling businesses, since the profit is based on service delivery 
requirements, the geographical layout of the routes and the actual size of the route. Therefore, any profit or loss would be based on rates established by the City. The rate structure, after modification of ordinances in each of the three cities was set by the municipalities.

Elected officials had information, based on financial reports, that garbage collection was a large revenue source for cities. Before losing that source of revenue, cities and counties would fight to keep control of the garbage collection program. For example, it's about a quarter of a million dollars in the Beaverton budget. For this reason, and because the source of revenue from refuse collection is stable, bureaucratic officials have not been interested in giving up revenue from fees charged to the garbage haulers. Also, public officials would not be interested in transferring solid waste regulation to another jurisdiction because of the likelihood of losing franchise fees as a stable revenue source.

In summary, bureaucratic officials have shown, through their planning process, a willingness to work with garbage haulers and citizens to plan a solid waste collection systems so that refuse haulers could meet new demands with some measure of assurance of rate protection, route protection, and working agreement protection.

Change in the System

Public laws, at the federal and state level, were passed to prevent certain materials from entering the waste stream. Changes occurred locally in 
the refuse collection industry because laws were passed to reduce the amount of garbage entering the solid waste stream; the public expressed concern about the type of solid waste and other forms of waste entering the landfills and, ultimately, the environment; because the local garbage hauling firms wanted protection from larger firms; and because the cost of disposing of solid waste increased. A major catalyst for change in the refuse collection industry in the three cities came in 1991 when Senate Bill 66 was passed by the State of Oregon with the intent to reduce the amount of materials entering the waste stream. Senate Bill 66 mandated recovery rates for local jurisdictions and established standards and goals for waste reduction programs. The Metropolitan Service District (Metro), a regional government, established regional standards for solid waste reduction programs that were to be implemented by local jurisdictions.

Since the passage of Senate Bill 66, solid waste became an issue for all cities in Oregon with populations over 4000. But the motivation for change in regulations also came in response to public concern for environmental conditions. One public official summed it up:

I think once people saw what was happening with the major landfill in the area, they said, "Whoa, what are we doing?" I think not only the city fathers said, "My gosh, what are we going to do with the garbage here," and the citizens said, "Whoa, what are we doing to the environment?" At least a percentage said that. ... I think, politically, 
once the realization [hit] that the area didn't have an infinite amount of space to get rid of their solid waste. ... they had to address it. And once they started addressing that issue, it forced them to address other solid waste issues concerning collection and recycling. ... (Interview, 015)

A plan was adopted by Metro which required participation by the three cities to reduce the solid waste stream and to take out recyclable materials. This plan included such requirements as curbside recycling and curbside yard debris programs.

The introduction of new requirements mandated by such laws as Senate Bill 66 stimulated new guidelines on the local level and forced bureaucrats to make policy decisions about garbage collection. These bureaucratic decisions have had a significant impact on the garbage collection industry in Portland. For example, the City of Portland established 3,000 as the number of houses in a franchised area. Because of this, some haulers were forced out of business, having to merge to survive or to quit altogether. A private hauler made the following statement:

For whatever reasons, the City established 3,000 as the number, and because of that, it took us off the street. This company has been doing this forever, but we lost the right to pick up curbside recycling. That was a big blow to us. So, that helped change our direction. (Interview, 005) 
This garbage hauling company stopped hauling garbage and began doing business in another part of the industry. One garbage company quit serving one jurisdiction and began serving another. Another garbage company sold to a larger company moving into the City of Portland. In Portland, policy decisions have effected garbage haulers serving the City. In the distant past there had been over 200 companies picking up garbage and taking it to the dump without regard as to what was in the solid waste stream; in 1992 there were 69 garbage haulers when franchising became effective doing this work. Bureaucratic decisions made to reduce the amount of materials in the solid waste stream and to recycle reusable materials created a need to change the manner of refuse collection and disposal. While decisions were being made out of concern for the amount of materials going into the waste stream, these decisions were also affecting residents as well as garbage haulers. Residents were affected by complicated rate charges. Residential rates were now based on size of the container, the location of the container, and the frequency of the pickup. Haulers were affected by the automation that was accompanying the changes in refuse collection. One public official reported the changes in this way:

[O]ur guys have had to ... figure out ... the best ways to do recycling. There has been some experimentation with using the same garbage truck. At the same time that recycling was coming in, automation was coming in. It used to be you'd see a garbage truck going down the street 
with a guy hanging off the back and he'd jump off and grab the garbage can and throw the lid off and throw the garbage in, throw the can back, and he went down the road; and he had to be pretty strong and physically fit to do the job.... And so automation was coming in and roll carts that you would roll out to the curb, the customer would roll out to the curb and an arm would come off the side of the truck and grab the cart and dump it in the garbage can. (Interview, 015)

Franchising, while welcomed by some haulers and not others, had the overall effect of changing the nature of garbage collection. With franchising came greater reporting requirements in order to keep the rate setting process equitable: The garbage haulers did not want to lose money performing recycling services, and each of the cities did not want to allow landslide profits to the garbage haulers. Also with franchising came the necessity for the garbage haulers to purchase new equipment to perform the recycling services. While the franchising efforts may have been fueled in part by the imperative of the Department of Environmental Quality and Metro to increase the recycling level and to reduce the waste stream to meet state and federal mandates, the net effect was a significant change for haulers operating in the City of Portland. One garbage hauler said this about the changes brought by recycling, which came with the switch to a franchised system:

We used to send one truck down the street. Now we send three. We send a truck down to pick up the garbage, we send a truck down to pick 
up their yard debris, and we send a truck down the street to pick up their recycling. (Interview, 016)

Many garbage hauling businesses experienced a reduction in business income because of route assignment by the City of Portland. A local hauler expressed his sentiments about franchising in the following manner:

We all have mixed feelings. All of the garbage companies do. 1 do too. Let me tell you why we wanted a franchise. The garbage haulers wanted a franchise because [outside garbage companies] were going around stealing our customers because of rates. So they were chopping up routes that we bought. You buy a route and it takes years to pay it off. You're making payments like buying a house, but it's many more times more expensive than the house. And here, when these guys are chopping up our routes and taking our customers for free, it's getting some bad feelings. And so, we wanted a franchise so that we would have a solid route, and the City wouldn't give it to us. When we explained to them, they wouldn't give to us. But when they wanted recycling and they wanted more items, we said we can't do that; Well, we had given all these freebies as it is. They were doing nine different items for recycling and doing it free, and we were paying the costs ourselves. Recycling does make money. And they said, well, we want you to add some more; we want you to do more things. We can't do that. So, they gave us a franchise. But it was the franchise [our area] 
that we wanted: We wanted our area. Well, they said, we'll give you that many customers, but it's not necessarily going to be in your area. (Interview, 013)

Routes were broken up and new assignments were based on such factors as the amount of revenues a business generated and not necessarily on where the garbage hauling business had been operating. Large companies could show large revenues based on overall operation rather than based on the number of residential customers that garbage hauling company had. The small company, while generating more tonnage of garbage hauled from residential homes, lost to the larger company that had less tonnage of garbage from residential homes. The route assignments affected revenues to the garbage hauler because the cost to deliver to the landfill was the same for the small company as for the large company.

Changes also occurred because of cost increases due to the closing of local landfills and because of the fear of competition. Local refuse collection haulers felt the threat of new refuse collection businesses moving into the area, creating intense competition. Early on, one garbage hauler said,

These guys from Sunflower and Cloudburst started up these routes and, God, all hell broke loose. They were threatening them out at the landfill and everything else: "You took that house down there on 27th and Vaughn, you took that house from me." "Well, no, it's a customer I signed up." "Well, you took it. I bought that house," the hauler 
would say. Now, at the same time, this huge company from back East came in and bought up a kind of a controversial guy. . . and this company is the world's largest . . . so everybody feared that the world's largest company would come in here and [take over]. So the net effect of what happened is that there was turmoil, and the haulers kept going to the City Council in ' 78, ' 82 or ' 83 and then in ' 87 with recycling plans. ... each time asking for franchising. (Interview, 020)

Recycling, a vehicle that stimulated change, brought two significant problems for the garbage haulers. The first problem was that of recovering the cost for pickup of the recyclable materials. The second problem was selling the recovered materials back to industry. Picking up recyclable materials is easy. Disposal of the recyclable materials is more difficult. Constant changes in market conditions affect how well recyclable materials could be disposed of. When prices were low, there was the possibility that the new requirements would force the garbage hauler to lose money. Haulers knew they were not supposed to lose money with the new state mandates. Therefore, rate structures had to include factors that would account for the possibility of loss. This was the dilemma: The cities were mandated to reduce the solid waste stream, but the garbage haulers could not be forced to recycle and lose money under the current operating guidelines. Garbage haulers felt they could not recover their costs in an open competitive system because their own commissioned studies had indicated that haulers can only 
recover about 30 percent of their costs from the markets. The other 70 percent would have to come from garbage rates. The three cities could not require the types of service delivery such as recycling under the service arrangements that were operating and so decided to make a change. Gresham and Beaverton already had regulated refuse collection services, but changes had to be made to insure that the cities could require service changes from the garbage haulers. Portland's entire system appeared outdated and unable to respond to the complications and changes that were coming from new requirements. Portland had to change from the open private competitive system to a regulated system because the open competitive system was inefficient could not be improved to a level that would achieve the desired service program. For example, in Portland three to four garbage hauling companies could be sending trucks down one the street at the same time. There was a lot of overlap in services which resulted in unnecessary burning of energy and polluting the air. In addition to this inefficiency was the fact that, under the private open competitive system, refuse haulers would not necessarily be offering recycling services to residential households. Requirements for recycling, as well as other solid waste reduction efforts, increased rates due to increased costs.

Portland, Gresham, and Beaverton City Councils became more proactive as costs increased and began to review rates for their service delivery systems. Rates have been very low for collection, and during the time when 
rates were low, there was not much public concern about garbage collection and disposal. As the rates began to increase, the level of interest increased for the residential customer and City councils. A garbage hauler indicated that Three years ago a company could go to the St. Johns Landfill and dump garbage for $\$ 17$ a ton at that landfill site. And a year and a half ago, a company could go out to the Hillsboro Landfill or Grabhorn Lakes Disposal and be charged by the cubic yard. Not for putrescible garbage, not for wet food garbage, but for building debris. But $\$ 17$ a ton, two and a half to three years ago, is now up to $\$ 79$ a ton. These prices were becoming more comparable to most landfills in other areas of the country. New Jersey for example is about $\$ 120$ dollars a ton. (Interview, 005)

The cost of tipping in the metropolitan area began to increase and there was no prospect that there would be any reduction or leveling out of prices in the near future.

Whereas twenty years ago there was little interest in the actual collection of household garbage and the attitude was, "As long as I don't see the garbage, as long as it's gone, I don't care about it; I don't care what happens to it" (Interview, 002), the realization of the problem seems to have come almost overnight. As one public official put it, "Now we've got to haul this garbage all the way to the middle of Oregon" (Interview, 015). This understanding of the garbage crisis compelled both public officials and garbage 
haulers to look at all the issues. Once city councils started to look at issues of closing landfills and increased costs, an awareness came that something had to be done and soon.

In summary, while no political campaigns have had garbage collection and disposal as a central campaign issue, solid waste has become a planning and management issue for city councils. This is due to landfill closures and state mandated requirements for recycling and the reduction of recycables and reusables from the solid waste stream. In order to achieve the mandated goals set by the State, a change was necessary in Portland that would end garbage collection and disposal as it had operated almost since the turn of the century. This is because the system, with its duplication and lack of formal rules, was inefficient (haulers crisscrossing each other's routes) and made achieving solid waste reduction goals almost impossible.

For the last 30 years, the type and level of garbage collection service had depended mostly on the garbage company. The garbage service could be as simple as picking up garbage and taking whatever was in the garbage can to the dump. Some garbage companies offered recycling, while others did not. Garbage collection has since become a process of collecting both recyclable and reusable materials along with non-reusables which requires additional handling of the recyclables and reusables and taking non-reusable materials to a transfer station. Garbage collection has become more competitive, more 
business like, and if the business cannot change to produce services in an efficient manner then there are consequences.

\section{Political Dynamics}

The political dynamics in each of the three cities were generally the same, and yet each city has had some specific dynamics of its own. In general, public opinion was supportive of recycling and supportive of the effort by government to do something about the environment.

Politically, Portland garbage haulers were the most active during the latter part of the 1970s, the 1980s, and the early part of the 1990s. Most of the political activities occurred in the form of lobbying City government. The garbage haulers took every effort to influence City government to adopt the programs they presented in hopes of obtaining the type of program that would benefit their businesses. This work was done to develop public policy which would take the garbage haulers through the transition phase of regulation and keep them in business. The lobbying effort took the form of influencing the City regarding the type of service arrangement that would be adopted for refuse collection. As one private hauler put it:

[There] has been a lot of work to develop public policy to support the local haulers through this transition, basically to keep them in the running. The City could have, in franchising the City garbage collection system, made a decision ... to put it out to bid to Waste Management or MDC or some bigger players. (Interview, 005) 
When lobbying did not achieve the desired results, the haulers resorted to other methods to achieve their goals, but only once did the garbage haulers demonstrate to present their message to the City. In December of 1986, garbage haulers drove their trucks around City hall for two days in protest: The haulers did not want to do curbside collecting and get the City into their businesses with a lot of regulations; on the other hand, the haulers did not want to lose the possible revenue either. Both these attitudes come from sixty years of doing business on their own and in their own way. There have, in the recent past, been reports of tires being slashed and trucks being burned within the garbage industry. This form of politics was noticed by the local garbage hauling industry and bureaucrats in Portland and did have some influence on decision-making.

Garbage haulers serving Portland did serve on public committees and represented their interest in this forum. Portland garbage haulers got some measure of protection with the franchise system. While no active political activities occurred in Gresham or Beaverton, garbage haulers did serve on planning committee in those cities and represented their interests in those forums. The garbage haulers serving Gresham got protection from outside business competition. Garbage haulers also came to public hearing in regards to refuse collection services.

Refuse collection has not traditionally been an issue that drove political campaigns. However, the issues that carried political weight in 
Portland were franchising (which included route assignments), rates, and rate setting, and recycling. The political issues for Gresham were recycling, rates, and rate setting. For Beaverton the political issues were rates and rate setting. One public official indicated that rates and rate setting have been the arena around which most political decisions revolve around in the three cities: "They revolve mostly around rates [and around] customer beliefs that rates are too high and hauler beliefs that rates are too low ..." (Interview, 007). This is particularly true of Beaverton and Gresham, [both of] which have established license systems (generally referred to as franchises). Because franchising came last to Portland, of the three cities, there was more at stake for the garbage haulers with the establishment of rates and the rate setting process.

The change from an open competitive system to a franchise system intensified political interactions between local garbage haulers and public officials in the City of Portland. Some of the garbage haulers took a proactive stand to voice concerns about the proposed franchise system for Portland. There was disagreement about the extent to which the City of Portland should regulate the garbage hauling industry. A compromise was reached to franchise only the residential portion of the garbage hauling industry. The disagreement over how much the City should regulate garbage haulers went as far back as the 1970s. In the early 1970s, the garbage haulers had proposed to the Portland City Council a plan for franchising in the City. The problem with 
franchising was that it could not occur with overlapping routes. Overlapping routes in the Portland system prevented efficiencies in service delivery and posed difficulties for achieving the goals set by new standards established by the state and regional government. As one public official noted,

In the '70s, the garbage haulers ... wanted government regulation. They didn't want the government to take over the collection, but they wanted what is called franchising, where the government assigns them a service area and adjusts the rates. They get a guaranteed business and a guaranteed rate of return. If the haulers hadn't kept pushing for that, the City would not have done anything. (Interview, 013)

As noted earlier, the garbage haulers protested a change (recycling) that they felt would not benefit their interest. As it turns out, however, it was the issue of recycling that helped push through the franchising package being considered by the City of Portland. Around 1990, recycling in the City of Portland became the major factor in the process of changing from an open system to a franchise system. This same public official quoted above indicated that

The City of Portland finally found a movement [recycling] that swayed people. Recycling as an issue gave government officials [a way that] people could accept franchising. Generally, people in refuse collection felt that government was going to take over the refuse collection business and felt garbage bills were going to go up. Those were the 
things that kept franchising from happening in Portland. Local officials in the City of Portland finally found the right argument at the right time. (Interview, 013)

As requirements associated with refuse collection became more complex, at least from a government perspective, public officials and private haulers began to become interested in the assurance that residents receive minimum levels of service, the different types of services available (e.g., recycling), and that these services meet the new requirements. While public officials focused on delivering minimum levels of service to residential customers and on reducing the materials in the solid waste stream, the haulers wanted to be assured that they would be able to recover their costs while providing new services to residential customers. Garbage haulers also wanted a way to comply with the new standards.

Both public officials and private garbage haulers indicated that franchising is not the perfect system, but then neither were the garbage collection systems operating prior to franchising. On the positive side, franchising protected the haulers from internal industry pressures, secured them financially when requirements were made of them to purchase specialized equipment to meet new legal requirements, and increased efficiency as the garbage haulers provided for a uniform level of service across the city. As the garbage business became more competitive and complicated, it also became obvious that rate setting and the rate setting process provided 
to haulers through franchising was a good deal because they received a measure of protection from outside competitive companies moving into the area. On the negative side was the implementation of new requirements (i.e., adjusting routes ) in the City of Portland. During this process, city officials worked mainly with the large garbage companies and encouraged very little public or small garbage company involvement. This selective involvement by public officials caused many garbage haulers to become upset about their lack of choice in route assignment and in the rate setting process. While garbage haulers in Gresham and Beaverton had more input into this governmental process, the City of Portland usied large garbage companies in its planning process and gave the large garbage companies more weight in the decision-making process than small companies as routes were being assigned. To understand the dynamics of franchising in the City of Portland, a brief narrative is needed on corporate activity just prior to implementation of the franchise system. The City of Portland was approached by three different organizations to develop a franchise system that would be based on a reduction in the amount of garbage in the waste stream. Prior to the implementation of such a franchise system in Portland, there were only three or four garbage businesses providing curbside recycling along with garbage collection. One of these companies was the first in the nation to do multiple pickups of garbage and recycling. The haulers, accustomed to doing business and providing services pretty much in their own way, did not want to do 
curbside collecting and recycling, but they did not want to lose the possible revenue to other companies, either. And whatever happened, they did not want the City of Portland overregulate the industry. However, when franchising seemed as if it was going to go through, regardless, the haulers protested.

Around the same time period, another form of corporate activity was taking place. Because of suspicion and fear, garbage haulers were guarded when talking about the interaction between individual companies and when reporting on specific corporate behaviors. Just prior to the adoption of the franchise system, where routes would be assigned and rates would be based on routes, garbage hauling companies began to use corporate tactics to influence the process and to maneuver their companies into positions that would allow them to gain maximum benefit. According to one informant, a case could be made that a very large company and others began working behind the scenes with a small local company that had been operating in Portland for years. These two companies maneuvered to maximize on the proposed changes that were to occur in Portland. To meet the soon to be proposed guidelines for route assignments, these two companies were probably the first companies in Portland to put out roller carts, and they came in way below the one-can rate. This is what caused suspicion: Both companies put out a 90 gallon can, which is about a three-can equivalent, and then the two companies began offering a price to pick up the garbage at a cost 
below the one-can rate. They then billed about 6,000 customers at this belowcost rate. Haulers wondered how any company could charge residential customers at below-cost rates to pick up garbage and continue to stay in business. It has been speculated that the two companies were underwritten by a holding company in another state. After a short while, the small local company that had been operating in Portland for years/went out of business, and the large company emerged as the owner of the smaller company. This consolidation is noteworthy because it happened just prior to the decision to franchise. It is also interesting because this large company, along with another large company, was able to work the pricing on curbside residential rates to get the City of Portland to factor in size of the cart to produce revenues when the City made decisions on route assignments. What that translated to is a very large company being allowed to obtain three large franchise areas because the franchise system, for route assignment and rate setting, is based on revenues rather than the ability of a garbage company to reduce the waste stream or to have an interest in recycling.

Garbage collection and disposal issues can become distorted by the political process, and when this happens programs suffer. There are times that local government will implement programs because it is politically expedient, but they do this without a clear plan for the whole process. Conversely, there are times when necessary programs are not implemented because of cost or because the program is not politically popular. Addressing 
the impact that public hearings had on the program development, bureaucrats in all three cities expressed that sometimes popularity was often the key as a way any change or new plan can get off the ground. In all three cities this was the case because the resolutions and ordinances which directed policies were developed by paid staff rather than by elected council members. Staff responded to perceived needs of the public and presented those needs to council in the form of proposed public policies. To paraphrase one public official, the recycling issue was politically popular, and that is why it got off the ground. It was one of the few activities that everyday citizens could do daily and have a positive environmental impact. When the question was raised, how could the resident become a good environmentalist? The answer was that they could recycle. While residents could not go out and plant trees or clean up water everyday, residents could do some recycling at home everyday. The people understood the importance of recycling and they got involved in it (Interview, 002).

Some decisions on recycling and garbage service were troublesome for planners and, in retrospect, difficult to explain. Yard debris is an example. The City of Gresham encountered a problem with its yard debris collection program. The problem with the yard debris collection program was its high cost. Gresham proposed a slight rate increase each month that would have provided for pickup of yard debris every other week, but there wasn't much public support for the cost increase. After study of public reaction, public 
officials returned to a monthly yard debris program and a smaller rate charge. Through this political move, Gresham was simultaneously conveying to the citizens the idea that there was no need for a more frequent collection system. This political move was done even though Gresham may be forced to adopt a bi-weekly yard debris program in the future. The interaction of politicians with programs frequently deprive both servers and the served of progressive efficient services. A public official commented on the public reaction to the yard debris program, noting that,

If there are 100 people who come down to the City Council meeting to complain about something, and the other ... don't show, you can either assume that they are in favor of the motion or they just don't give ... one way or the other. But [City Council] will try to find some way to appease the ... 100 people that showed up. That's what happened to us on the yard debris program. [Residents] were screaming and shouting and carrying on ... they didn't want to pay for yard debris collection. (Interview, 002)

Sometime political agendas get in the way of sound program development; times a program is developed that would be advantageous to residents and the garbage haulers, yet it cannot be implemented because of political agendas. The yard debris program (as originally designed) seemed as if it would be the correct program and in the long run be the least expensive and easiest to manage, yet it became distorted because of politics. In the end, what was 
implemented was a hybrid program, which may not work as well nor meet original expectations. Decisions got caught in politics. Programs that were designed to increase productivity and minimize complaints suffered. Informants indicated that, generally, refuse collectors provided services to residential customers with few complaints. Considering the number of households served and how small the number of complaints have been, it can be said that there have been no complaints. For this reason there has also been no pressure to develop a monitoring system. However, a review of the records revealed detailed procedures to respond to complaints by residential customers. Portland and Gresham do have a formal process to address complaints between the residential customer and the refuse hauler. Procedures for residential customers to lodge complaints in Beaverton were less formal. One public official indicated that there were about 90 pages of administrative rules that establish standards in Portland for the refuse hauler to follow. The administrative rules covered a range of procedures that may not be important to some, yet may be very important to others, such as the fact that garbage collection starts at six o'clock in the morning. Another procedure addressed is regarding when the garbage hauler misses a house (and with a franchise system a customer does not have a choice of refuse collectors). If that happens, the City insures that the refuse collector goes back and picks up the garbage from that house (Interview, 004).

The City of Portland's Bureau of Environmental Services (1991) in its 
administrative rules has a process by which to notify the garbage hauler of a complaint and procedures for resolving those complaints in a timely manner. In Beaverton, where 20,000 households and 4,000 businesses are served, there have been occasional complaints about service. However, in the past when there was a rate review, no citizens came to council hearings to complain to the City Council about rates. There have been no complaints in writing nor in oral presentations at the hearings. Within the City of Beaverton there has been no government policy or bureaucratic movement toward monitoring complaints or developing a program that would need to be complaint driven. Complaints are resolved when reported, and should a garbage hauler receive too many complaints, the complaints will be reviewed at the rate review. There have been no "garbage police" to monitor the refuse collection. The small number of complaints at any given time suggests that the public is satisfied with the services being delivered (Interview, 007).

In summary, because of the proposed changes that were being studied by the City of Portland, the haulers were actively seeking to influence the outcome in a manner that would best benefit their companies. Haulers used lobbying, active demonstration, and business tactics to influence bureaucratic decision making. Gresham and Beaverton already had established assigned routes when mandates came to reduce the solid waste stream; therefore most of their issues centered around rates and the rate setting process. Garbage haulers serving on planning committees contributed to program 
development in Gresham and Beaverton. While recycling was an issue in each of the three cities, it was seen as a pivotal issue in Portland.

\section{Uniform Implementation}

Policies for solid waste disposal are uniform and are monitored by Metro. Disposal is the end point where solid waste is taken for final disposition. Metro has legal authority for disposal (landfill and incineration). For example, garbage can only be taken to a Metro facility. Policies for refuse collection however are not uniform because each city or jurisdiction is responsible for refuse collection. Refuse collection is the initial point where solid waste is picked up. While refuse collection is similar due to state mandate, refuse collection services are not uniform. This is because each jurisdiction has responsibility for the collection of garbage from residential households. With present political structures, uniform implementation for solid waste collection would have to be initiated simultaneously by each local government for government uniformity to occur. A uniform solid waste collection system requires intergovernmental cooperation. It: also would require cooperation for policy development, and policies that create uniformity would have to be advantageous for the public. One public official posed these questions on the subject:

Is there a reason why Beaverton would want to adopt | [Portland's ordinances] or why we would want to rescind some of ours because 
other jurisdictions are more relaxed than ours? I don't think that we want to turn over our decisions to somebody in another county. (Interview, 004)

A rational argument can be made for having some form of uniform policy throughout the region, wherein governments come together to determine which policies should be adopted and then agree to implement those adopted policies. However, it would be difficult for one overall policy to be adopted by all jurisdictions for residential refuse collection. As another public official points out, "It's difficult to do because you are dealing with subjurisdictions that have franchises with private haulers. .." (Interview, 015). Also, each level of government has a stake in the financial security of their jurisdiction. One difficulty that could prevent uniform implementation is that local jurisdictions assess the garbage haulers a percentage of the rate charged to the residential customers to offset administrative costs. A regional regulation would mean a regional uniform rate. One question City Council might ask is what the current rate for one jurisdiction is in comparison to the rates in other jurisdictions. If the one rate is lower than the others, the question might be: Why should the rate in this jurisdiction go up? If the rate is higher, the question might be: How will costs be covered with lower rates? Should rates go up beyond the garbage hauler's expenses, how will that problem be adjusted? Should revenues drop and the haulers fall into a nonprofitable position, how will that problem be resolved? 
Councils would want to know how regional regulations would benefit residents in their jurisdiction. One garbage hauler said, The difficulty ... is that Portland is in there with their five percent handout, Tigard is over here with their three percent handout, the county is getting their three percent. Everybody is getting a portion of the fees that are being paid for this service to offset their administrative costs. (Interview, 021)

If another legal entity began to regulate the collection of residential refuse from households, the administrative fees would most likely be collected by the agreed upon jurisdiction responsible for setting policies for solid waste collection. The same garbage hauler continued with this comment:

Because if you assume that the local jurisdiction has administrative costs now, which they're paying out of these fees, then a new entity that is going to regulate the entire region also is going to have administrative costs that they have to get from somewhere. (Interview, 021)

Costs and rates are based on such factors as density of population, labor, and distance to the disposal site. For a uniform system of residential refuse collection to occur, the agreed upon governmental entity would have to assume responsibility for setting rates and standards.

\section{Recycling}

While recycling has historically been a part of the garbage collection 
process, the approach to recycling was one of recovering those unwanted materials that had resale value. The early philosophy for recycling was that picking up anything of value for resale was "junking" rather than recycling. The effort was individual rather than uniform. In the early 1970s the philosophy regarding use began to change and people in society began seeing recycling as a method to both reduce the solid waste stream and save the environment. The Oregon Bottle Bill, passed in 1971, gave a big push toward the philosophy of recycling.

Mandated recycling services have changed the garbage collection business. State statute required that recycling be performed and that the garbage hauler should not lose money. Recycling, as mandated, has increased the cost of doing business and in some instances has reduced the profit margins for some companies.

Private haulers suggested that residential customers were paying more for garbage collection with recycling than without it. One hauler indicated his costs had increased because he was sending three trucks down the street as opposed to one. He could get rid of the same material with one truck, but obviously he wouldn't be doing any recycling of materials. Local officials expressed a desire to develop a mechanism to make recycling easier for the residential customers and the hauler. Public officials also expressed a desire to work out a method to make it economically feasible for manufacturing companies to use recycled materials. 
There are two major obstacles in the way of using recyclable materials. One obstacle is that there are more tax benefits for using raw materials than for using recycled materials. The second obstacle is that the price for recyclables fluctuates based on the demand of manufacturing companies.

There are requirements for the handling of hazardous waste and recycling and regulations that drive the entire process to reduce the waste stream. In the past the garbage hauler would pick up anything the residential customer put out on the curb. Now hazardous waste (e.g., household paint) is left for the customer to dispose of in another manner. Plastic can be difficult to recycle because residential households can generate lots of it and garbage haulers cannot sell it because the market is inconsistent and unstable. One garbage hauler indicated he had about 25,000 pounds of plastic in storage and had no place to send it. Nobody seemed to want it. The choice was certainly not to put the plastic into the ground.

The question asked most often is this: Does recycling have a positive environmental impact? The answer is not simple. For materials that can be recycled, recycling is effective in reducing the solid waste stream. However, there are many products that just cannot be recycled, given today's technology and the demand for raw materials. While recycled materials are used in the production of paper products, metals, and plastics, virgin material has the advantage of consistency in quality. Companies must incur huge expense to retool in order to incorporate recycled materials. While contamination is not 
a factor for the production of steel or aluminum, contamination can compromise the quality and marketability of glass, plastics, and paper. Management Technologies

Information about management technologies in this study came from twelve garbage haulers serving the three cities. Eleven of those garbage haulers were small businesses. Two were new businesses operating in the area. One was a large garbage hauling business. The majority of the businesses reporting management technologies used by their companies were small and family owned. For these businesses, management was most likely to be all one level. That is, the driver of the truck might also have been the owner of the company or a relative of the owner of the truck, and the bookkeeper might have been the owner's wife. One owner reported his entire business income as the amount spent on labor.

The general response from garbage haulers was that the types and levels of service provided to residential customers were required as a part of the franchise or license agreement for the City in which they did business. All three cities have ordinances that require garbage haulers to offer curbside collection once a week to residential customers. The rate structure discourages other types of frequency choices as well as places (e.g., back yard) where a residential customer might want to have the garbage picked up. One garbage hauler indicated the following:

The customer has a choice: he can have weekly pickup or he can have 
monthly pickup. Those are the two rates that are set. If he chooses not to have regular pickup, then the customer can have on-call service. The rates are structured to discourage that. They have structured rates to try to encourage people to get service weekly. (Interview, 019) The type of service, whether it is recycling, garbage collection, or yard debris collection, is set by the City. The type of container, frequency, and the placement of the container is also set by the City. In reference to level of services and billing arrangements, one private hauler made the following statement:

[The City] controls how we bill, when we bill, our service levels, our pricing, everything is controlled by the City now. Everything is mandated anymore. The condition of your trucks, the working hours, how you bill, when services can be terminated and for what reasons. (Interview, 010)

Management technologies information obtained from garbage hauling companies is as follows: tons of refuse picked up per year, frequency (times/week) and location of pickup, number of households served per year, number of households served each 8 hour shift, number of tons collected per 8 hour shift, percentage of shift driving to and from the disposal site, other types of refuse other than mixed refuse picked up on regular route, percentage of total cost spent on labor, percentage of total cost spent on equipment, workers being on an incentive system, crews being checked on and crew size. 
Table 3 below summarizes the management technologies variables.

Table 3

Management Technologies

\begin{tabular}{llc}
\hline Variable & Low & High \\
\hline $\begin{array}{l}\text { Percent of shift spent } \\
\text { driving to and from } \\
\text { disposal site }\end{array}$ & $3 \%$ & $33 \%$ \\
\hline
\end{tabular}

Amount of time spent driving to and from the $15 \mathrm{~min} . \quad 90 \mathrm{~min}$. disposal site

Number of types of refuse other than mixed refuse picked up on regular route

0

7

Percent of total cost spent on labor $12 \% \quad 40 \%$

Crew size 1 2

Cost of equipment $10 \%$ $25 \%$ 
Table 4 below summarizes the management technologies variables.

Table 4

Management Technologies

\begin{tabular}{lcc}
\hline Variable & Yes & No \\
\hline Crews checked on & 4 & 8 \\
\hline $\begin{array}{l}\text { Workers on incentive } \\
\text { system }\end{array}$ & 5 & 7 \\
\hline
\end{tabular}

For refuse collection in the three cities, eight of the businesses reported that crews were checked on and four reported that the crews were not checked on. Seven businesses reported that workers were not on any type of incentive system and five reported workers being on an incentive system. The percent of the shift driving to and from the disposal site was reported to be as low as 3 percent and as high as 33 percent. The amount of time spent driving to and from the disposal site was as low as 15 minutes and as high as 90 minutes. The number of types of refuse other than mixed refuse picked up on regular route was reported to be as low as 0 and as high as 7 . The percent of cost spent on labor was a low of 12 percent and a high of 40 percent. The crew size was a low of 1 and a high of 2 . Not all firms responded to these questions. Summary

The history of residential refuse collection is important because it 
shows how the current system evolved, it details the beginning and growth of residential refuse collection in the three cities, it provides some of the rationales for the system that is currently operating, and it gives personal viewpoints from the people involved in the system who assisted in bringing about its current structure. Until the early 1970s, there was less bureaucracy and interference by government in the operations of the garbage collection business. The relationship between government and private garbage companies was less formal and less antagonistic. Because of the passage of federal and state mandates to reduce the quantity of materials entering the solid waste stream, garbage collection evolved into a formal process guided by these mandates and by administrative rules. In general terms, the driving force for change in residential refuse collection was a new awareness by government for the need to reduce the amount of solid waste entering the solid waste stream.

Public officials and private haulers suggested that legal requirements and labor were connecting factors that contributed to the process which helped shape decision-making for the type of municipal service delivery arrangement chosen for refuse collection in each city. Both private garbage haulers and public officials suggested that recycling and other mandated programs changed the nature of the garbage collection business. Service arrangements established locally by each of the three cities changed in response to mandates from regional and state governments. Municipal 
policy for refuse collection for the City of Portland had been an open system where private non franchised haulers collected garbage from residential homes. This was changed to a franchise system. Municipal policy for refuse collection for Beaverton and Gresham changed from a franchised system to a licensed system. All these systems moved toward greater regulation of the residential refuse collection business. These changes, while seemly minor in nature, actually gave those cities more ability to manage refuse collection effectively and to respond to mandated requirements from the State of Oregon.

Because of the waste disposal problems, refuse collection became more complex and complicated as government mandated changes to reduce the waste stream through a process of recycling, reuse, and the adoption of standards for initial packaging. Recycling, as mandated, increased the cost of doing business and, in some instances, reduced the profit margins of some companies. Other changes occurred because of new technology used to assess the results of chemicals being put in landfills and the reactions those chemicals have on the ecological system.

Public officials in Gresham and Beaverton reported that those two cities were continuing with the same refuse haulers and that haulers had retained the same districts and customers and were still providing the same basic collection service. In Portland, public officials reported that the city was continuing with the same refuse collection haulers but that route 
assignments had been adjusted to create efficiencies for the new franchise system.

Franchising was welcomed by most of the refuse collection haulers but not all of them. Some of the haulers felt left out of the planning process and felt forced to conform to rules that were detrimental to their individual businesses. In Portland, the planning process had the expressed purpose of achieving efficiencies while keeping current refuse collection haulers in business. In Gresham and Beaverton, the planning process was more involved in rate setting for the refuse collection haulers and program development to meet new mandated requirements.

The rationale for a particular service arrangement was influenced by the experiences of the people making decisions about service arrangements, the political climate of the municipality, and in the case of all three cities, a desire to not put current residential refuse collection haulers out of business.

Public officials and private haulers in these cities indicated that history, traditions, legal requirements, and labor were among those factors significant for decision-making regarding the type of municipal service delivery arrangement chosen for refuse collection. Portland, Gresham, and Beaverton have had few complaints. The small number of complaints at any given time has been interpreted as public satisfaction with services being delivered. Route assignments were established to create efficiencies and meet 
new state mandates to reduce the amount of materials entering the solid waste stream. 


\section{Chapter 6}

\section{ANALYSIS AND CONCLUSION}

\section{Qverview}

Refuse collection appeared to be evolving with few external challenges until the latter part of the 1970s when state and regional governmental mandates began to put pressure on cities, which in turn put pressure on garbage haulers, to conform to a complex and complicated sets of rules in an industry where there had been few rules in the past. Because of the waste disposal problems associated with the closing of local landfills, refuse collection and disposal became more complex and complicated than ever before. In response, government adopted new laws and set up a mechanism for monitoring implementation to insure that the solid waste stream would be reduced; and without setting up a municipal collection system, Portland, Gresham, and Beaverton have been able to comply with the new Oregon State laws. The cities achieved this by adopting ordinances which gave them more control over the collection of garbage and allowed them to define what would be considered reusable or recyclable and what would be sent to the disposal site. The ordinances that gave the cities more control changed the local refuse collection industry. Garbage collection and disposal is no longer an equation of pick up and dump equals service. The old "out of sight, out of mind" adage no longer works. With legal mandates and regulations, garbage has been defined and specified, its methods of retrieval (manual or mechanical) determined, and the routing of vehicles for collection and 
disposal have been codified. While few rules had been the norm for refuse collection in the three cities, in a short space of time, new mandates created vast changes.

The choice in service arrangement for refuse collection is not simple and, as has been noted in the literature, the methods by which service arrangements are chosen can be a matter of tradition, or maybe even mythology, but not necessarily rational planning. While the method for deciding service arrangements in the three cities was clearly not mythology, I have found that bureaucrats made decisions about the choice for the type of service arrangement for their particular city by focusing on such nonmonetary factors as tradition and the needs of the garbage haulers. Bureaucrats in each of the three cities took into consideration the fact that a service delivery system had existed for years and then made decisions accordingly. Legal requirements and labor were also connecting factors which contributed to the process that helped shape decision-making for the type of municipal service delivery arrangement chosen for refuse collection in each city.

My theory, that government makes policy decisions regarding alternative service arrangements for refuse collection services based on nonmonetary factors, is supported by the data from the three cities studied.

\section{Relevance of Literature}

The literature has been used to incorporate municipal refuse collection 
as a service arrangement, because this arrangement does not exist within the three cities studied, and to provide a theoretical framework from Public Choice and Urban Policy and Analysis through which to relate to the themes that emerged from interviews. For example, public choice literature provides information on the advantages and disadvantages of options when selecting a service arrangement for delivering of when delivering a public service through private organizations. Theories from public choice and urban policy and analysis are included to provide a theoretical framework from which to view the behavior of bureaucrats in the three cities under study. The theory of managerial behavior from public choice literature suggest that private firm managers and government agency bureaucrats will behave in a particular manner under certain sets of inputs when making decisions. In public choice literature bureaucratic behavior is explored in the context of constraints that would either impede or encourage specific behaviors, and that the choices of inputs will influence whether a bureaucrat will choose to expand or not and under what conditions. Urban Policy and Analysis theoretical framework on contextual processes, suggests a relationship between political dynamics and the interactions of influences that impact decision-making within bureaucratic processes. The bureaucratic process has a cyclical influence in that one actor's behavior re-enforces the behavior of another. The cycle, itself, maintains the bureaucratic process, which in turn provides stability to the system. The Urban Policy and Analysis theory of incrementalism describes a 
decision-making process within which in a series of decisions made over a period of time becomes a policy making strategy. The process of decisionmaking by bureaucrats over an extended time creates an environment of contextual influence. It is the confluence on decision-making that has an impact on bureaucratic process.

While some of the behaviors and decision-making processes of the bureaucrats relate to public choice theory and urban policy and analysis frameworks, other behaviors could not be accounted for with these theories. For example, when making choices in service arrangements, city bureaucrats did not appear to have been involved in expansion activity over the years, though theory would suggested this was likely. Although the opportunity did exist, bureaucrats in the three cities did not choose to expand staff when changes were being made in service arrangements. Bureaucrats in all three cities did appear to use the incremental approach to creating public policy. In all three cities, decisions by bureaucrats are small, ongoing, and made as a way to adjust to new requirements for residential refuse collection in the three cities.

Attribution theory in Social Psychology literature has been included in this analysis to account for how time and perception, as nonmonetary factors, are important in understanding the decision-making process of bureaucrats in the three cities. Attribution theory in Social Psychology literature can account for the why bureaucrats would make inferences about garbage 
haulers while choices are being made about residential refuse collection services.

\section{Evaluation of Themes}

The data that emerged from my study have been evaluated regarding the role that history played in the overall development of refuse collection, the influences and events which impacted the decision-making of bureaucrats, the nature of the interaction of political cultures and the impact this had on decision-making for policy, and the responses to the options that were available to bureaucrats when making choices for a service arrangement. The data have also been evaluated in order to demonstrate those aspects of residential refuse collection the three cities under study. What follows is a breakdown of this evaluation by' theme area. Several of the themes from the findings chapter have been subsumed under other themes. For example, Background, Changes in the System, and Uniform Implementation, as themes, are addressed within the other themes rather than as separate areas.

The qualitative methods used in grouping sets of data is intended to facilitate the interpretation of events of the three cities from the early 1900 to the present. Inferences have been made to so that understanding can occur when evaluating similarities of events being presented. What follows is a breakdown of the evaluation by theme areas based on similarities of data presented in interviews. 
History. Routes are at the core of the garbage hauling businesses.

Routes were traditionally important to the garbage haulers because the size of the route determined the income for the business. Early franchise agreements in Gresham and Beaverton established and regulated the garbage haulers residential routes. Later franchise agreements not only established residential routes, they established service delivery within these residential routes for the garbage haulers. As you will recall, residential refuse collection in Portland was an open unregulated system. Routes were protected by the garbage haulers themselves, not through the regulatory process of government. As each of the three cities' planning efforts moved toward establishing more control so that the city could achieve its goals, routes and rates were connected together in order to get the haulers to perform the necessary services. Originally, the cities could not require the haulers to deliver a specified type of service to residential customers because: Little direct involvement of government in the operation and delivery of refuse collection services over the garbage hauling businesses meant also that government had little direct control of the types of services being delivered to residential customers. In order to get the necessary control to accomplish their new goals, each city could have chosen to develop and deliver municipal services. All three cities chose instead to find ways to obtain the necessary control while continuing with current haulers. Incremental theory can account for the manner in which bureaucrats made decisions to continue 
with the current haulers rather than setting up an entirely new system to deliver refuse collection services. The bureaucrats were consistent in making decisions within the context of tradition and making changes withlin the context of the politics of the city.

Tradition. Time is central for an activity to become tradition. Time and a series of activities connected together is what garbage haulers had that established their activities as tradition. How garbage haulers established and maintained routes, transferred their businesses, and provided services, became the basis for tradition.

Tradition, as a nonmonetary factor in decision-making, is evident in the planning and management of the service by Portland bureaucrats prior to the development of the franchise system. Tradition impacted the planning and management strategy used by bureaucrats to deliver residential refuse collection services. For example, the option for municipal refuse collection was dismissed because the current haulers had always been used to collect the garbage. Gresham chose to continue with the current haulers becaluse of the perception that the haulers had always done a good job and there was no need to change it. Portland's planning was focused on keeping residential refuse collection on the private side. Beaverton indicated the issue of municipal refuse collection had been resolved long ago and was no longer a factor under consideration. Thus, planning for residential refuse collection began with a premise that stemmed from tradition. The use of tradition in the $/$ planning 
and management strategy employed by bureaucrats in Gresham and Beaverton is seen in the institutional protection provided for haulers in those cities through the ordinances which established the routes. Tradition is also seen in the choices to grandfather haulers into the franchised system along with the routes which they had established over the years.

Prior to the franchise system in Portland, garbage haulers established their own routes, | and each garbage hauler respected the other's route. This respect was due in part to tradition, but if the route was not respected on the basis of tradition, there were other methods to reinforce the integrity of a haulers's route. The manner in which garbage haulers enforced their routes aside, bureaucrats in Portland helped reinforce the integrity of the hauler's route by allowing haulers to assign customers to individual routes. This manner of customer assignment had been practiced for years; tradition was reinforced by unofficial bureaucratic blessing. There were no formal ordinances or administrative rules that established the manner in which Portland allowed the garbage haulers to assign customers to a hauler's route. Along with customer assignment to individual routes, bureaucrats in Portland left pricing, billing, and level of services to the garbage haulers. Practices established in these areas became the norm for the operation of residential refuse collection and continued until the franchise system was establișhed in 1992.

The transition in Portland from a open private, competitive system to 
a regulated franchised system for residential refuse collection had two major effects. The first effect was the movement away from a less formal, less controlled delivery system where the open market determined rates charged for services and market business practices determined which company would be delivering services to which customer. The second effect was the stability the haulers gained as a byproduct of the regularity of use by the city and the protection the city provided for their established routes. The haulers received protection, from outside competition, of routes that had been established by local haulers over the years. This change protected small local companies from large outside companies moving into the market. The consolidation of routes through route assignments and the standardization of services promoted efficiencies in service delivery and thus gave the garbage haulers another avenue for stabilization. The route assignment helped stabilize local businesses through the rate setting process, which ensured companies a level of income.

Tradition is the one advantage the garbage haulers have had in each of the three cities. Investment in the traditional ways of operating kept bureaucratic planning away from specific service arrangement possibilities (e.g., contract or municipal collection) and guided the planning activities toward an alternative choice of service arrangement. Tradition, as a nonmonetary factor, became the rationale for continuing with local garbage collection businesses. This rationale is seen in the statements made about 
refuse collection haulers in the three cities: These businesses have always provided this service in the city; the garbage businesses can provide the service cheaper than government; the local garbage hauling businesses have the necessary expertise to do the work. While cost may have been the foremost postulated rationale for the selection of service arrangement, tradition simply became the factor that kept the local garbage haulers delivering services. Cost was not the central factor. Contracting with one or two large companies could have possibly achieved the same cost saving results. However, as bureaucrats pointed out, companies already operating in the cities were quite old, had always been doing these types of services, and had a great deal of experience. In the end, it boiled down to this idea: "We can't put these folks out of business who have been doing this business for 50 to $8: 0$ years" (Interview, 004).

While there is the common belief that cost is the overriding factor that determines choice in service alternatives, there are other factors that influence choice, such as legal considerations, traditions, the number of potential suppliers of the desired service, strong opposition from other sources, and large start-up costs associated with a municipal refuse collection and disposal system. Each of these factors were expressed in interviews by both garbage haulers and public officials. While the literature does not point conclusively to how choices are made in selecting a service arrangement, clearly the decision-making by bureaucrats in these three cities was guided by 
the tradition of the garbage hauling companies that had been operating locally since the turn of the century. Tradition and history also influenced the decision-making process which created stabilization for the garbage haulers, insuring their continued use as changes were being made in refuse collection services.

Service Arrangements. As the three cities responded to mandates to make changes in refuse collection services in order to reduce the solid waste stream, choices for service arrangements were not considered because of the influence of tradition on the planning process. All interviewees reported that there was virtually no discussion for the implementation of a municipal refuse collection system as the service arrangement alternative in any of the three cities. Choices for bureaucrats, in the decision-making process, became limited to a few options because of the influence of tradition and the lobbying, both direct and indirect, by the garbage haulers. In all three cities, policy decisions regarding service arrangement for refuse collection were made with consideration for the service delivery system that currently existed. Changes were made only to meet new demands.

While there was not any serious discussion for a municipal refuse collection system in the three cities due to the influence of the garbage haulers, the decision to franchise came in part as a matter of economics: Each city was receiving revenue into its general fund from the current refuse collection system. A change in the current financing structure or mechanism 
could have had political consequences for bureaucrats and politicians. The literature indicates that when any municipality has implemented municipal collection with city employees, the cost for those services increase to the point where the service becomes a major budget item, and those cities with municipal refuse collection have significantly higher costs than those cities receiving services from private enterprise. By contrast, my study of franchised or licensed systems with private garbage haulers the three cities shows that income was generated into the general fund because of the rates charged to garbage haulers to perform the service in each city. A tax requirement by government would have changed refuse collection from an optional, private interaction between a hauler and a resident to a service that could become mandatory because all taxpayers would be required to pay the tax. This would have been a significant change for residents. Bureaucrats desired to avoid going to the taxpayer to ask for a new tax in order to operate refuse collection services that have already been in operation for years and were not willing to risk the political challenges that would be created by such a change. Bureaucrats had a clear incentive to make the choice for private delivery of residential refuse collection rather than encounter the political backlash for an unpopular decision. Given the choice between implementing a new tax and continuing to provide residential refuse collection under a franchise agreement with a fee assessed to the garbage haulers, the behavior of the bureaucrats could have been predicted. 
In the three cities, bureaucratic decisions regarding criteria for the measurement of service delivery arrangements for refuse collection were made with consideration for the service delivery system that currently existed and with an attempt toward keeping formal evaluations as informal as possible. While Portland's refuse collection system was too new to have any experience for how measurement of its program would occur, Gresham and Beaverton bureaucrats used rate setting as the process to evaluate program delivery. The assumption was that, as long as the refuse collection services were being delivered without complaints, there was no need for separate formal evaluations.

Bureaucracy. Throughout their planning processes, bureaucratic officials have worked with garbage haulers and the public in the formulation of policy for residential refuse collection. Bureaucrats in all three cities engaged in activities such as setting up public hearings and including haulers on planning committees in order to solicit input while also responding to mandates to reduce the amount of materials entering the waste stream.

Planning by bureaucrats in Portland centered on recycling and the inefficiencies of the system that was operating before franchising. There decisions were based on the rationale that recycling is necessary because of closing landfills. Planning decisions to eliminate inefficiencies in residential refuse collection in Portland were centered on the idea that there were too many garbage haulers and that the smaller the number of haulers the greater 
the efficiency for recycling. Recycling continues to be a central planning issue in bureaucratic planning in Portland. Planning by bureaucrats in Gresham and Beaverton relied on recycling as a central theme to achieve state mandated goals. Because of the necessity of achieving the mandated goals, bureaucrats in these two cities made policy decisions for refuse collection using recycling as the rationale.

Stated rationales for the selection of service arrangements used in the Portland, Gresham, and Beaverton include:

1. The desire not to put established garbage haulers out of business.

2. The belief that the established garbage haulers could deliver the systems needed.

3. The desire to protect the established garbage haulers.

4. The belief that there would be high capital start up costs for a municipality to begin to deliver a municipal refuse collection service.

5. The belief that there was an adequate supply of available garbage haulers to provide the service.

These rationales, all nonmonetary factors, continue to be central in bureaucratic planning in the three cities. Bureaucrats in Portland, Gresham, and Beaverton, developed residential refuse collection programming that maximizes benefits (through rates) to the city. For example, rather than 
starting and operating a utility service with huge start-up costs, which could also be labor intensive, bureaucrats opted to propose ordinances to allow private haulers who were already delivering refuse collection services to continue to do so. Through this choice bureaucrats maximize benefits to themselves while not avoiding the development of large bureaucracies to manage refuse collection services. In effect, the service arrangernent option chosen by bureaucrats is seen as better than that of a municipal collection.

The literature has indicated that privatization can act to ayert a financial crisis for cities by reducing infrastructure costs. The bureaucratic choice in type of service arrangement eliminated the possibility that financing residential refuse collection would become an issue for political budget debate in the three cities because the refuse collection program, as implemented, is income producing. Because the service arrangement options for each of the three cities actually contribute income to city budgets through their rate setting processes, bureaucrats are not likely to recommend cities change the financing mechanism.

While managerial behavior theory suggests that government agencies have incentive to increase the size of their staff, the staff managing all three cities' residential refuse collection services have been small and continue to be small. As Portland, Gresham, and Beaverton made changes in their refuse collection delivery systems, there was no sharp increase in the staffing requirements to maintain those regulated services chosen by each of the 
cities. The small staff responsible for refuse collection services in Portland is part of a larger bureau. The staff responsible for refuse collection services in Gresham is small. Refuse collection functions are distributed to several staff members in several departments in Beaverton. In fact, in Beaverton, only hours of staff time from several departments are dedicated to refuse collection. Data from interviews suggest that bureaucrats continue to rely on the garbage haulers to manage and deliver residential refuse collection services without extensive government involvement. Based on established tradition and the relationship that garbage haulers have with bureaucrats, garbage haulers are seen as being capable of delivering excellent services and therefore not in need of extensive monitoring.

Political Dynamics. Because Beaverton and Gresham already had established franchise for residential refuse collection, the planning process was involved primarily in rate setting for the haulers and in program development to meet new mandated requirements. For is reason, the main political agendas in these two cities revolve around rates, rate setting, recycling, and licenses. Franchising was new in Portland and therefore the main political issue in that jurisdiction.

The garbage haulers were a powerful lobby in the planning process. The power of their lobby came from the bureaucrats perception that: 1) the haulers had started the residential refuse collection business and thus knew it better than anyone; 2) the haulers had a long history and tradition of 
delivering services to residential customers; and 3) the haulers were already delivering the residential service and could deliver a the service with regulation at a cost less than government. It is these perceptions of the garbage haulers that allowed them to influence many of the decisions being made. Bureaucratic perception is a specific nonmonetary factor in the three cities studied. It helped the small, family-owned business to be retained as a service delivery option at a time when powerful, large companies were moving into the Portland market and pressuring bureaucrats to establish contracts with one or two large companies.

Recycling. Recycling is the issue bureaucrats used to implement a regulated garbage collection program in Portland. Initially, bureaucrats in Portland had difficulty in getting garbage haulers to accept recycling as a part refuse collection. After the State mandated requirements to reduce the solid waste stream and haulers objected, bureaucrats in Portland moved ahead without consensus of the garbage haulers. Because the garbage haulers had lobbied for protection of their routes, bureaucrats in Portland were able to get haulers to accept recycling by including it as part of the franchise package. The bureaucrats had two problems: 1) responding to mandates to reduce the solid waste stream and 2) a refuse collection system in operation in which the City of Portland had very little control. Bureaucrats in Portland took the single issue of recycling to force haulers to accept franchising, which gave bureaucrats the control necessary to adequately respond to state mandates. 
Bureaucrats focused on one pivotal issue to make the necessary changes.

Management Technologies. Management technologies identified by garbage haulers in the three cities were similar to those presented in the Stevens study. Garbage haulers providing residential refuse collection services in the three cities developed technologically (in equipment) as well as organizationally (in management practices) along with the industry in the U.S. This shows that garbage collection companies in Portland, Gresham, and Beaverton were progressing along with other garbage companies in the U.S. and were not operating in a vacuum in Oregon. Management technologies of the three cities were categorized in the same manner as municipal garbage hauling systems. As such, the internal management operation of the garbage companies advanced as well as the mechanical operations performed tasks similar to other garbage hauling companies in other U.S. cities. Like other garbage companies operating in the U.S., the garbage companies in the three cities keep records on frequency of service, quality of service, and level of service. Garbage companies in my study are also concerned with the amount of shift time taken to drive to and from the disposal site, the types of refuse and other mixed refuse picked up on the regular route, the amount of money spent on labor and equipment, the frequency and quality of service delivery, and the quality of the job that was delivered by the crew member on the job. Unlike municipal service delivery systems, private companies in my study were concerned with rates and rate 
setting by the municipal government because rates determined the level of profit.

Information from the literature suggests that municipal refuse collection in U.S. cities has the possibility for funding from a variety of municipal mechanism, the most common being the tax base. Like other $U, S$, cities shown in the literature, the service arrangement that was planned and implemented by bureaucrats in the three cities meets the needs of the garbage haulers and the cities they serve.

\section{Conclusion}

In this study of three cities, nonmonetary factors such as bureaucratic behavior and pressures for change came together to influence decisionmaking in the area of service arrangements. The literature on alternative service delivery arrangements emphasizes measuring efficiencies in terms of cost, management, quality of service, and frequency of the service delivery. However, after assessing nonmonetary factors in decision-making in this study, I found that these three cities were influenced by the weight of history and tradition, legal mandates, industry pressures, and the lobbying efforts of the garbage haulers.

While the literature is inconclusive regarding the relative efficiency for public and private organizational arrangements providing the same service, I found that the choice in service delivery arrangements for each of the three cities supports the position that private organizational arrangements can 
achieve the goals of government. The three cities chose private delivery of services as part of a process of making the necessary adjustments in current refuse collection service delivery systems to meet new mandates. The three cities were able to achieve the goal of reducing the solid waste stream by using recycling as a device to gain more control over the residential refuse collection services without actually producing the service. The franchise/license systems designed by the cities moved the garbage haulers toward functioning as regulated utilities. The franchise/license relationship between the cities and private haulers allows the haulers to remain private, gives the necessary control to the city, and provides the service to residents without mandating it. In Portland, franchising stabilized residential refuse collection for the haulers by providing protection and granting legitimacy to the haulers' route.

The use of a single criterion in determining choice of private organizational forms (e.g., the belief that cost alone will produce the best service option) may not create the results desired by municipal governments. Public tasks (in this case, refuse collection) are best delivered when the tasks can be measured and public oversight has been established for quality control. I found that the three cities had clear and measurable guidelines for the operation of refuse collection services, even though the use of the guidelines was seen as unnecessary by the local bureaucrats. Each of the three cities used multiple criteria when planning and monitoring service delivery for 
residential refuse collection services. In the planning process, bureaucrats in the three cities used multiple criteria to determine the type of service arrangement that would best operate in their city. While cost was one criteria, there were many other nonmonetary criteria used in the decisionmaking process.

Bureaucrats and garbage haulers continually influence and reinforce each other with input from multiple sources in the decision-making process. Bureaucrats are able to get the results they want even though they have chosen to not enlarge city bureaucracy to obtain control of residential refuse collection. Instead, bureaucrats achieved the desired results by moving private haulers toward the role of a utility. In this manner, the haulers could remain private and make private business decisions to deliver refuse collection services and the bureaucrats could have the necessary control to achieve the goals of government.

Policy Implications

Both the literature and data from the study offer insight into the ongoing bureaucratic task of planning for residential refuse collection services. The choice in selection of a service arrangement for refuse collection services is not a simple process. In this process, there are two important aspects: 1) the array of service arrangement options that can be developed and used to meet a specified need, and 2) the contextual 
environment that bureaucrats operate within that influences the decisionmaking process.

Choosing a particular service arrangement based on the idea of efficiency or cost alone may not achieve desired results for the municipality. When reviewing options for a service arrangement, bureaucrats could benefit from a search of nonmonetary factors that may have influence on decisionmaking in the city. Planners will most likely produce better results if the history and tradition of the community are included along with such factors as cost. It is also important to have clear definitions of the tasks to be performed, when using private delivery of public services.

The literature suggests that service arrangements (whether license, franchise, or contract) should include language ensuring that there is little room for waste and inefficiencies. Continued efforts should be taken to define evaluation criteria to insure that services being delivered can be monitored with measurable criteria. Public tasks considered for private delivery are best delivered when the tasks can be measured in quantitative terms. As evaluation of the service should include an examination of the type of service arrangement being used in the municipality. The evaluation should also include the type of arrangement used, the level of service (including frequency, kinds of pickup, crew size, etc.) and how rates are established and maintained. Even though bureaucrats in the three cities did 
not engage in a formal evaluation process, they did none-the-less have an evaluative process established.

Policies for refuse collection should contain provisions for competition to prevent undesirable results from the operation of monopoly license/franchise systems. Criteria used to adopt a refuse collection system would ideally be based on such nonmonetary factors as the history and tradition of the people living in the city.

When bureaucrats are faced with choices surrounding policy questions for carrying out government programs through private means, information from the history and tradition of the workers in the area under review can provide an understanding of policy issues. 


\section{SOURCES CONSULTED}

(1994). "Recycling, Is It Worth the Effort?" Consumer

Reports. 59, 92-95.

$59,91$.

(1994). "Guilt-Free Guide to Garbage." Consumer Reports.

Agar, Michael H. (1986). Speaking of Ethnography. Newbury Park: Sage Publications, Inc.

Ahlbrandt, Roger S., Jr. (1973). "Municipal Fire Protection Services:

Comparison of Alternative Organizational Forms." Administrative \& Policy Studies Series. 03-002, 1-72.

Baum, Bernard and Parker, Charles H. (1973). Solid Waste Disposal: Reuse / Recycle and Pyrolysis. Vol. 1. Ann Arbor, MI: Ann Arbor Science Publishers, Inc.

Baum, Bernard and Parker, Charles H. (1974). Solid Waste Disposal : Reuse / Recycle and Pyrolysis. Vol. 2. Ann Arbor, MI: Ann Arbor Science Publishers, Inc.

Beck, R.W. and Associates. (1991, February). Solid Waste Collection/Recycling Rate Study: Final Report, prepared for the City of Gresham, OR.

Bellafante, Ginia. (1990). "Minimizing Household Hazardous Waste." Garbage: The Practical Lournal for the Environment. 1, 45.

Bourne, Barry S. (1967). Private Development of the Central City. (Research paper No. 112). Chicago: Department of Geography, University of Chicago.

Bozeman, Barry. (1988, March/April). "Exploring the Limits of Public and Private Sectors: Sector Boundaries as Maginot Line." Public Administration Review.

Breen, Bill. (1990). "Landfills are \#1." Garbage: The Practical Journal for the Environment. 2, 42-47.

Carlson, Donald. (1990). Metro, Portland, OR. Interview. 
City of Beaverton, Oregon. (1980). Solid Waste Collection and Disposal and Related Matters, Ordinance No. 3176.

City of Beaverton, Oregon. (1989). Solid Waste Collection and Disposal and Related Matters, Resolution No. 2971.

City of Beaverton, Oregon. (1990). Solid Waste Collection and Disposal and Related Matters, Resolution No. 3060.

City of Beaverton, Oregon. (1990). Changing the Duration of Solid Waste Licenses from Five Years to Ten Years and Related Matters, Ordinance No. 3757.

City of Gresham, Oregon. (1989). Solid Waste Collection Districts Study. Citizen Advisory Committee.

City of Gresham, Oregon. (1988). Community and Economic Development Department. Solid Waste Collection Study Report. Solid Waste Collection Study Citizen Advisory Committee.

City of Gresham, Oregon. (1989). Community and Economic Development Department. Summary of Solid Waste Advisory Committee's Recommendations and Implementtion Actions. Solid Waste Collection Study Citizen Advisory Committee.

City of Portland, Oregon. (1991). Administrative Rules Residential. Bureau of Environmental Services.

City of Portland, Oregon. (1990). Bureau of Environmental Services. Interim Beport to Council on the Status of the Solid Waste Collection System in Portland.

City of Portland, Oregon. (1990). Recommendations for Change to Portand's Solid Waste Collection System. Bureau of Environmental Services.

City of Portland, Oregon. (1988). Report by the Office of the City Auditor. Street Maintenance: Opportunities to Improve Quality and Lower Costs. City of Portland.

City of Portland, Oregon. (1991). Bureau of Environmental Services. Solid Waste and Recycling Rate Study. 1.

City of Portland, Oregon. (1976, January). Refuse Collection Permits, Ordinance No. 140919, Chapter 17.102. 
City of Portland, Oregon. (1992). Solid Waste and Recycling Collection, Ordinances No. 164916 and No. 165001.

City of Portland, Oregon. (1991). Grant Residential Solid Waste, Recycling and Yard Debris Collection Franchises in the City of Portland, Ordinance No. 164701.

Clark, Terry Nichols. (1985). "Urban Policy Analysis." Annual Review of Sociology. 11, 437-455.

Clark, Terry Nichols. (1981). “Urban Policy Analysis: Directions for Future Research." Urban Affairs Annual Review. 21, 13-22.

Crew, Michael A. and Twight, Charlotte. (1990). "On the Efficiency of Law: A Public Choice Perspective." Public Choice. 66, 15-36.

Danhof, Clarence H. (1968). Government Contracting and Technology Change. Washington, D.C.: The Brookings Institution.

DeHoog, Ruth Hoogland. (1984). Contracting Out for Human Services: Economic, Political, and Organizational Perspectives. New York: State University of New York Press.

Donahue, John D. (1989). The Privatization Decision: Public Ends, Private Means. Basic Books.

Dunleavy, Patrick. (1986). "Explaining the Privatization Boom: Public Choice Versus Radical Approaches." Public Administration. 64, 13-34.

Dye, Thomas R. (1978). Understanding Public Policy. Third Edition. Englewood Cliff, N J: Prentice-Hall.

Elliot, Jeffrey M. and Ali, Sheikh R. (1988). The State and Local Government Political Dictionary.

Fisk, Donald, Kiesling, Herbert, and Muller, Thomas. (1978). Private Provision of Public Services: An Qverview. Washington, D.C.: The Urban Institute.

Guba, Egon G. (1985). "What Can Happen as a Result of a Policy?" Policy Studies Review. 11-16. 
Gershowitz, Harold. (1977). "Contracting for Solid-Waste-Management Services." In: Handbook of Solid Waste Management. David Gordon Wilson (Ed.) New York: Litton Educational Publishing, Inc.

Hanke, Steve H. (1983). "On Privatizing Urban Infrastructure." A Report Submitted to the Office of Policy Development and Research U.S. Department of Housing and Urban Development. HUD-0003221 Baltimore, MD.

Hahn, Harlan and Levine, Charles H. (1984). Readings in Urban Politics: Past, Present, and Future. Second Edition. New York: Longman, Inc.

Hatry, Harry P. (1983). A Review of Private Approaches for Delivery of Public Services. Washington, D.C.: The Urban Institute Press.

Holmes, Hanna. (1990). "Cities Fight for Right to Recycle." Garbage: The Practical Journal for the Environment. 2, 20-23.

Holmes, John R. (1981). Refuse Recycling and Recovery. Chichester: John Wiley \& Sons.

Hula, Richard C. (1986). “Introduction: Market Based Public Policy." Policy Studies Review. 5, 583-587.

Johnson, Gerald W. and Heilman, John G. (1987). "Metapolicy Transition and Policy Implementation: New Federalism and Privatization." Public Administration Review. 47, 468-478.

Kourik, Robert. (1990). "What's So Great About Seattle?" Garbage: The Practical Journal for the Environment. 2, 24-31.

Kroll, Martin. (1962). "Hypotheses and Designs for the Study of Public Policies in the United States." Midwest Journal of Political Science. 4.

McAfee, R. Preston and McMillan, John. (1988). Incentives in Government Contracting. Toronto: University of Toronto Press.

McCracken, Grant. (1988). The Long Interview. Newbury Park: Sage Publications, Inc. 
McGuire, Robert A., Ohsfeldt, Robert L., and Van Cott, T. Norman. (1987). "The Determinants of the Choice Between Public and Private Production of a Publicly Funded Service." Public Choice. 54, 211230.

McLean, Iain. (1987). Public Choice: An Introduction. New York: Basil Blackwell, Inc.

Mead, Lawrence M. (1985). "Policy Studies and Political Science." Policy Studies Review. 5, 319-335.

Mitchell, William C. (1988). " Virginia, Rochester, and Bloomington: Twenty-five Years of Public Choice and Political Science." Public Choice. 56, 101-119.

Mladenka, Kenneth R. (1984). "The Urban Bureaucracy and the Chicago Political Machine: Who Gets What and the Limits to Political Control." In: Readings in Urban Politics Past, Present, and Future. Harlan Hahn and Charles H. Levine, (Eds.). New York: Longman Inc.

Moe, Ronald C. (1987). "Exploring the Limits of Privatization." Public Administration Review. 47, 453-460.

Moe, Ronald C. and Stanton, Thomas H. (1989). "Government-sponsored Enterprises as Federal Instrumentalities: Reconciling Private Management with Public Accountability." Public Administration Review. 49, 321-329.

Morrison, Peter A., Vaughn, Roger J., Vernez, George, and Williams, Barbara R. (1979, March). Recent Contributions to the Policy Debate. Santa Monica, CA: The Rand Corporation. [R-2394- RC]

Morrison, Peter A. (1989, June). The Rand Corporation, Santa Monica, CA. Interview.

Murin, William J. (1985). "Contracting as a Method of Enhancing Equity in the Delivery of Local Government Services." Lournal of Urban Affairs. 7, 1-10.

Newman, Herbert E. (1968). An Introduction to Public Finance. New York: John Wiley \& Sons, Inc. 
Oregon, State of. (1983). Oregon Revised Statutes, Public Contracts and Purchasing. 279.011 to 279.063 .

Ostrom, Vincent and Bish, Frances Pennell (Eds.). (1977). Comparing Urban Service Delivery Systems: Structure and Performance. Beverly Hills, CA.: Sage Publications, Inc.

Pack, Janet Rothenberg. (1990). "The Determinants of the Choice Between Public and Private Production of a Publicly Funded Service Reconsidered." Public Choice. 66, 183-188.

Peterson, Paul E. (1981). City Limits. Chicago: The University of Chicago Press.

Pfaffenberger, Brian. (1988). Microcomputer Applications in Qualitative Research. Newbury Park, CA: Sage Publications, Inc.

Rathje, William L. (1990). "The History of Garbage." Garbage: The Practical Lournal for the Environment. 5, 33.

Rein, Martin. (1970). Social Policy: Issues of Choice and Change. New York: Random House, Inc.

Rein, Martin and Rainwater, Lee (Eds.). (1986). Public/Private Interplay in Sorial Protection: A Comparative Study. New York: M.E. Sharpe, Inc.

Rich, Richard C. (1982). Analyzing Urban-Service Distribution. Massachusetts: D.C. Heath and Company.

Ross, Elizabeth. (1992). "Boston Recycles Sludge into Fertilizer." The Christian Science Monitor. 15.

Rubin, Herbert J. (1986). "Local Economic Development Organizations and the Activities of Small Cities in Encouraging Economic Growth." Policy Studies Journal. 14, 363-388.

Savas, E.S. (1977). The Organization and Efficiency of Solid Waste Collection. Massachusetts: D.C. Heath and Company.

Savas, E.S. (1977). "Policy Analysis for Local Government: Public Versus Private Refuse Collection" Policy Analysis. 3, No. 1, 49-74. 
Savas, E.S. (1982). Privatizing the Public Sector. Chatham, NJ: Chatham House Publishers, Inc.

Schon, Donald A. (1977). Beyond the Stable State. New York: W.W. Norton and Company, Inc.

Starling, Grover. (1988). Strategies for Policy Making. Chicago: Dorsey Press.

Starling, Grover. (1979). The Politics and Economics of Public Policy: An Introductory Analysis with Cases. Homewood, Ill: Dorsey Press.

Strauss, Anselm and Corbin, Juliet. (1990). Basics of Qualitative Research: Grounded Theory Procedures and Techniques. Newbury Park, CA: Sage Publications, Inc.

Stevens, Barbara J. (Ed.). (1984, June). Delivering Municipal Services Efficiently: A Comparison of Municipal and Private Services Delivery. New York: Ecodatra, Inc.

Stevens, Barbara J. (1980). Handbook of Municipal Waste Management Systems: Planning and Practice. New York: Litton Educational Publishing, Inc.

Sullivan, Harold J. (1987). "Privatization of Public Services: A Growing Threat to Constitutional Rights." Public Administration Review. $47,461-467$.

Swartzbaugh, Joseph T., Duvall, Donovan S., Diaz, Luis F., and Savage, George M. (1993). Recycling Equipment and Technology for Municipal Solid Waste: Material Recovery Facilities. Park Ridge, $N$ J: Noyes Data Corp.

University of Oregon, Bureau of Governmental Research and Services. (1988). Refuse Collection and Recycling: Practices and Regulation.

U.S. Department of Health, Education, and Welfare, Bureau of Solid Waste Management. (1970) Municipal Refuse Disposal. Public Administration Service. Chicago. 
U.S. Department of Health, Education, and Welfare, Bureau of Solid Waste Management. (1970). Mathematical Modeling of Solid Waste Collection Policies. Vols. 1 and 2. Washington D.C.: U.S. Government Printing Office.

U.S. Department of Housing and Urban Development Office of Community Planning and Development. (1986). Outstanding Local Partnerships in Community Development Programs and Projects.

Vesilind, P. Aarne and Rimer, Alan E. (1981). Unit Operations in Resource Recovery Engineering. Englewood Cliff, NJ: Prentice-Hall, Inc.

Waldman, Steven. (1990, March). "The Peril of Private Enterprise." Newsweek.

Wilson, David G. (Ed). (1977). Handbook of Solid Waste Management. New York: Van Nostrand Reinhold Co.

Wolf, Charles Jr. (1988). Markets or Governments: Choosing Between Imperfect Alternatives. Cambridge, MA: The MIT Press.

World Wildlife Fund. (1991). Getting at the Source: Strategies for Reducing Municipal Solid Waste. Washington, D.C.: Island Press.

Zardkoohi, Asghar and Giroux, Gary. (1990). "Bureaucratric Behavior and the Choice of Labor Input: A Study of Municipal Governments." Public Choice. 64, 185-190. 
Primary Data and Information

Interviewees

\begin{tabular}{|c|c|c|}
\hline Name & Organization & Interview Dat \\
\hline Adams, Jack & $\begin{array}{l}\text { Public Official } \\
\text { City Councilor, City of Gresham }\end{array}$ & Oct. 15, 1992 \\
\hline Bisbee, Gary & $\begin{array}{l}\text { Public Official } \\
\text { City of Beaverton }\end{array}$ & Oct. 13, 1992 \\
\hline Boitano, Susan & $\begin{array}{l}\text { City Sanitary } \\
\text { Owner, City of Portland }\end{array}$ & Oct. 23, 1992 \\
\hline Brittingham, Max & $\begin{array}{l}\text { Private Employee } \\
\text { Nan-profit corp. - statewide }\end{array}$ & Sept. 9, 1992 \\
\hline Carlson, Eric & $\begin{array}{l}\text { Public Official } \\
\text { City of Beaverton }\end{array}$ & Sept. 30, 1992 \\
\hline Ege, Terry & $\begin{array}{l}\text { Ege Sanitary Service } \\
\text { Owner, City of Gresham }\end{array}$ & Sept. 2, 1992 \\
\hline Erlendson, Beth & $\begin{array}{l}\text { Public Official } \\
\text { City of Beaverton }\end{array}$ & May 7, 1992 \\
\hline Garofalo, John & $\begin{array}{l}\text { Sunflower Recycling, lnc. } \\
\text { Business Manager, City of } \\
\text { Portland }\end{array}$ & Oct. 23, 1992 \\
\hline Hamburg, Don & $\begin{array}{l}\text { Don's Garbage Service } \\
\text { Owner, City of Beaverton }\end{array}$ & : Sept. 17, 1992 \\
\hline Helzer, William & $\begin{array}{l}\text { Alberta Sanitary Service } \\
\text { Owner, City of Portland }\end{array}$ & Oct. 9, 1992 \\
\hline Hohnstein, George & $\begin{array}{l}\text { Valley Garbage Service } \\
\text { President, City of Beaverton }\end{array}$ & Oct. 16, 1992 \\
\hline Kampfer, Dean & $\begin{array}{l}\text { Alpine Disposal and Recycling } \\
\text { Owner, City of Portland }\end{array}$ & Oct. 8, 1992 \\
\hline
\end{tabular}




\begin{tabular}{|c|c|c|}
\hline Kies, Delyn & $\begin{array}{l}\text { Public Official } \\
\text { Washington County, Oregon }\end{array}$ & Sept. 3, 1992 \\
\hline Kotta, Lynda & $\begin{array}{l}\text { Public Official } \\
\text { Solid Waste Program Manager } \\
\text { City of Gresham }\end{array}$ & May 29, 1992 \\
\hline Miller, Mike & $\begin{array}{l}\text { Gresham Sanitary } \\
\text { Owner, City of Beaverton }\end{array}$ & October, 1992 \\
\hline Miller, Tom & $\begin{array}{l}\text { Miller's Sanitary Service } \\
\text { Owner, City of Beaverton }\end{array}$ & October 6, 1992 \\
\hline Oakley, Richard & $\begin{array}{l}\text { Baldwin Sanitary Service, Inc. } \\
\text { Owner, City of Portland }\end{array}$ & Sept. 10, 1992 \\
\hline Penner, Scott & $\begin{array}{l}\text { Waste Management of Oregon } \\
\text { Vice President, City of Portland }\end{array}$ & Sept. 18, 1992 \\
\hline Scott, Nancy & $\begin{array}{l}\text { Public Official } \\
\text { City of Beaverton }\end{array}$ & Oct. 9, 1992 \\
\hline Walker, Bruce & $\begin{array}{l}\text { Public Official } \\
\text { City of Portland }\end{array}$ & Sept. 29, 1992 \\
\hline Webster, Leonard & $\begin{array}{l}\text { American Sanitary Service } \\
\text { Owner, City of Gresham }\end{array}$ & Sept. 22, 1992 \\
\hline
\end{tabular}


Appendices

Reproduced with permission of the copyright owner. Further reproduction prohibited without permission. 
APPENDIX A

INFORMED CONSENT

Reproduced with permission of the copyright owner. Further reproduction prohibited without permission. 


\section{INFORMED CONSENT}

I, hereby agree to serve as a subject in the research project entitled "Government Policy and Private Organizational Forms: Analysis of Refuse Collection and Disposal in Metropolitan Cities" conducted by Thomas J. Wright, a graduate student at Portland State University.

I understand that the study involves an hour long interview that will be taped recorded. Notes of the interview will also be taken.

I understand that possible risks to me associated with this study are inconvenience and a demand on my time.

It has been explained to me that the purpose of the study is to learn about public decision making and refuse collection in this metropolitan area.

I may not receive any direct benefit from participation in this study, but my participation may help to increase knowledge which may benefit others in the future.

Thomas J. Wright has offered to answer any questions I may have about the study and what is expected of me in the study. I have been assured that all information I give will be kept confidential and that the identity of all subjects will remain anonymous.

I understand that I am free to withdraw from participation in this study at any time without jeopardizing my relationship with Portland State University.

I have read and understand the foregoing information and agree to participate in this study.

Date Signature

If you experience problems that are the result of your participation in this study, please contact the Chair of the Human Subjects Research Review Committee, Office of Grants and Contracts, 345 Cramer Hall, Portland State University. (503) 725-3417. 


\section{APPENDIX B}

\section{Definitions}

The definitions that follow are taken from (1) the Institute for Solid Wastes of American Public Works Association, (2) the city ordinances of Portland, Beaverton, and Gresham, (3) Vesilind and Rimer (1981), (4) Harry P. Hatry, (1983), and (5) the Bureau of Governmental Research and Service (1988).

Garbage:

Garbage is the animal and vegetable waste resulting from the handling, preparation, cooking, and serving of food. The term does not include food processing waste from canneries, slaugherhouses, packing plants, or similar industries.

- Municipal Refuse Disposal

Rubbish:

Rubbish consists of a variety of both combustible and noncombustible solid wastes from homes, stores, and institutions, but does not include garbage.

- Municipal Refuse Disposal 
Household Refuse:

A combination of mixed garbage and rubbish from residential households. Included are: food, yard debris, paper products, plastics, rubber, leather, textiles, wood, metal, glass, and earth materials.

- City of Portland

Recycling:

'Recycling' means the series of activities, including collection, separation, and processing, by which products or other materials are recovered from or otherwise diverted from the solid waste stream, (1) for use in the form of raw materials in the manufacture of new products other than fuel and (2) in the case of source separated wood waste which has no material use, for use as fuel. Recycling includes composting of source separated organics but not composting of mixed waste.

\section{- City of Portland}

Residential Refuse Collection:

The pickup and removal of refuse from households and small commercial establishments which are served on the same routes and with the same equipment as is used to serve households. The service is defined to include collection only; costs incurred after collection vehicles are emptied (whether into a transfer 
trailer, a landfill, or the pit of a resource recovery plant) are not included in the costs of refuse collection. Residential refuse collection almost always includes the collection of mixed (kitchen and other nonputrescible) household wastes. Other types of waste generated by households (such as leaves and yard debris, bulky items, or source-separated items such as newsprint or glass) may or may not be collected on the regular refuse collection routes using the same crews and equipment as is used to pick up mixed household waste.

Solid Waste:

'Solid Waste' has the meaning given in ORS 459.005, including but not limited to garbage, rubbish, refuse, ashes, discarded home appliances, manure, vegetable or animal solid and semisolid wastes and other waste generated by commercial customers; but not including:

a. sewage sludge, septic tank and cesspool pumping or other sludge

b. discarded or abandoned vehicles

c. recyclable material or yard debris which is source separated and set out for recycling purposes

d. waste that is designated by the Oregon State Department of Environmental Quality (DEQ) or Metro as requiring special handling, treatment, storage, or disposal to avoid potential 
damage to the environment or to public health, such as infectious waste or hazardous waste.

\section{- City of Portland}

Characteristics of Refuse:

Moisture content, Particle size, Composition by materials (steel, paper), Chemical composition (carbon, hydrogen), Density, and Mechanical properties.

- Vesilind and Rimer, 1981

Other types of refuse are: Street refuse, Dead animals, Abandoned vehicles, Industrial refuse, Demolition refuse, Consiruction refuse, Sewage, Waste, Hazardous or Special refuse. A complete listing and definitions can be found in Municipal Refuse Disposal, 1970.

Alternative Approaches for Delivering Refuse Collection Services Contracting Out:

A municipal government enters into a contract agreement with a private firm to provide goods or deliver services. The private firm bills the municipal government rather than billing the residential customer.

Franchise:

Municipal government awards an exclusive or nonexclusive agreement with a private firm to deliver a service for a specified 
amount of time. Usually there are regulatory conditions with the franchise agreement. The private firm bills the residential customer rather than billing the municipal government. The municipal government sets the rate the private company can charge and sets the rate of profit return. Services delivered by the private firm are limited to a specific area.

License:

License agreements function like a franchise agreement. Under the license agreement, there are provisions for the conditions of the license agreement. The license agreement allows for the municipality to regulate service standards, set service areas, and approve rates for the services to be delivered. A license system gives more flexibility and control to the municipality for regulatory authority.

Municipal:

Local government provides the service using public employees within a governmental department such as public works. The service is financed through a tax structure or the customer is charged a fee for services. Services generally are mandatory to all residents within the governmental jurisdiction. 
Private Nonregulated Competitive:

Private firms offer services directly to the residents and negotiate fees with the customer based on the competitive market.

Usually there is little government regulation other than a municipal business license. 
APPENDIX C

Landfill Cost (Tipping Fees)

Amount Per Ton

\begin{tabular}{|c|c|c|}
\hline YEAR & COST & LANDFILLTRAANSFER STATION \\
\hline Pre- 1988 & $\begin{array}{l}\$ 16.90 \\
\$ 19.70\end{array}$ & $\begin{array}{l}\text { St. Johns Landfill } \\
\text { Clackamas Transfer Station }\end{array}$ \\
\hline 1 Nov. 1988 & $\$ 42.25$ & $\begin{array}{l}\text { St. Johns Landfill } \\
\text { Clackamas Transfer Station }\end{array}$ \\
\hline 1989 & $\begin{array}{l}\$ 42.25 \\
\$ 44.75\end{array}$ & $\begin{array}{c}\text { St. Johns Landfill } \\
\text { Clackamas Transfer Station } \\
\text { Metro Transfer Station }\end{array}$ \\
\hline 1990 & $\begin{array}{l}\$ 49.85 \\
\$ 55.00\end{array}$ & $\begin{array}{c}\text { St. Johns Landfill } \\
\text { Clackamas Transfer Station } \\
\text { Metro Transfer Station }\end{array}$ \\
\hline 1991 & $\$ 56.85$ & $\begin{array}{c}\text { St. Johns Landfill } \\
\text { Clackamas Transfer Station } \\
\text { Metro Transfer Station }\end{array}$ \\
\hline 1992 & $\$ 75.00$ & $\begin{array}{c}\text { St. Johns Transfer Station } \\
\text { Clackamas Transfer Station } \\
\text { Metro Transfer Station }\end{array}$ \\
\hline
\end{tabular}

